\title{
slit: an extracellular protein necessary for development of midline glia and commissural axon pathways contains both EGF and LRR domains
}

\author{
Jonathan Marc Rothberg, ${ }^{1}$ J. Roger Jacobs, ${ }^{2,3}$ Corey S. Goodman, ${ }^{2}$ and Spyros Artavanis-Tsakonas ${ }^{1}$ \\ ${ }^{1}$ Howard Hughes Medical Institute, Departments of Cell Biology and Biology, Yale University, New Haven, Connecticut \\ 06520 USA; ${ }^{2}$ Howard Hughes Medical Institute, Department of Molecular and Cell Biology, University of California, \\ Berkeley, Berkeley, California 94720 USA
}

\begin{abstract}
The Drosophila slit locus encodes a protein with four regions containing tandem arrays of a 24-amino-acid leucine-rich repeat (LRR) with conserved flanking sequences (flank-LRR-flank surrounding these arrays), followed by two regions with epidermal growth factor (EGF)-like repeats. Each of these motifs has been implicated in protein-protein interactions as part of an extracellular domain in a variety of other proteins. Analysis of slit cDNA clones reveals that as a consequence of alternative splicing, the locus can code for two distinct protein species differing by 11 amino acids at the carboxyl terminus of the last EGF repeat. The existence of a putative signal sequence and the absence of a transmembrane domain suggest that slit is secreted, an observation supported by an analysis of its expression in tissue culture. Examining the expression pattern of slit in the embryo by antibody staining, enhancer trap detection, and in situ hybridization, we demonstrate that the protein is expressed by a subset of glial cells along the midline of the developing central nervous system. Through immunoelectron microscopy, slit can be seen on the commissural axons traversing the glial cells although it is absent from the cell bodies of these neurons, implying that slit is exported by the glia and distributed along the axons. Finally, we demonstrate that a reduction in slit expression results in a disruption of the developing midline cells and the commissural axon pathways. The embryonic localization, mutant phenotype, and homology of slit to both receptor-binding EGF-like ligands and adhesive glycoproteins suggest that it may be involved in interactions between the midline glial cells, their extracellular environment, and the commissural axons that cross the midline.
\end{abstract}

[Key Words: EGF; leucine-rich repeats; axon pathways; glia; Drosophila]

Received July 13, 1990; revised version accepted September 19, 1990.

Proteins containing epidermal growth factor (EGF)-like sequences have been shown to play an important role in many aspects of eukaryotic cell control, acting as signals for proliferation, growth inhibition, and differentiation. A common feature of these proteins is their involvement in extracellular events and ligand-receptor interactions. In characterizing genomic DNA identified by cross-hybridization to the sequence coding for the tandem EGF repeats of Notch, a gene involved in Drosophila neurogenesis, we previously reported the isolation and partial characterization of sequences from an unlinked locus that codes for EGF repeats. We showed this sequence to correspond to the slit locus and established that null mutations result in disruptions of the embryonic central nervous system (CNS) (Rothberg et al. 1988).

3Present address: Department of Biology, McMaster University, Hamilton, Ontario, Canada L8S4K1.
The involvement of slit in cell interaction events is suggested by the presence of EGF-like repeats in the deduced protein sequence. Furthermore, both in situ hybridization and antibody staining of embrycs demonstrated that the highest level of slit expression is restricted to a special group of six midline glial cells that interact with and later enwrap developing commissural axons. Together, these findings were of particular interest, given the mutant phenotype and the evidence that, in both vertebrates and invertebrates, glial cells participate in neural outgrowth through cell-cell contact and the secretion of diffusible factors (Bastiani and Goodman 1986; for review, see Vernadakis 1988). The appearance of a glial scaffold in Drosophila before axonal outgrowth (Jacobs and Goodman 1989a), as well as the extension of pioneer growth cones along the surfaces of these glial cells, suggests that these glia play an instructive role in the determination of the major axon pathways in the CNS (Jacobs and Goodman 1989a,b). 
Thus, we became interested in determining what role slit might play in the development of the midline glia and the commissural axon tracts.

Here we report the full structure of the slit protein, as well as its sites of production and distribution. We find that in addition to containing EGF homologous domains, the slit protein also has four regions bearing homology to the leucine-rich repeats (LRRs) found in a family of proteins involved in protein-protein interactions (Titani et al. 1987; Schneider et al. 1988; McFarland et al. 1989; Field et al. 1990; Krantz and Zipursky 1990). In addition, we show that sequences flanking the LRRs of slit exhibit homology to sequences in corresponding positions in some of the other LRR-containing proteins. We demonstrate that slit is necessary for the normal development of the midline of the CNS, including particularly the midline glial cells, and for the concomitant formation of the commissural axon pathways. Furthermore, this process is dependent on the level of slit protein expression. We also present evidence indicating that the slit protein is excreted from the midline glial cells where it is synthesized and is eventually associated with the surfaces of the axons that traverse them. In addition, slit protein is tightly localized to the muscle attachment sites and to the sites of contact between adjacent pairs of cardioblasts as they coalesce to form the lumen of the larval heart. The implications of the structure and distribution of the slit protein in development are discussed.

\section{Results \\ Molecular characterization of the slit transcript and P-element alleles}

The isolation and partial characterization of slit EGF-homologous genomic sequences and corresponding cDNA clones was described previously (Rothberg et al. 1988). Here we extend our molecular analysis to include the entire slit-coding sequence, its genomic organization, characterization of a splicing variant, and the molecular basis of four P-element-induced mutations. The slit embryonic transcript was estimated to be $\sim 9 \mathrm{~kb}$ by Northern analysis. Using both conventional hybridization screening procedures and methods employing the polymerase chain reaction (PCR), we obtained cDNA clones representing $8.3 \mathrm{~kb}$ of this sequence /see Materials and methods|. Sequencing of genomic DNA indicates a consensus Drosophila transcriptional initiation sequence (Hultmark et al. 1986) 53 bp upstream of our longest $\mathrm{cDNA}$. Figure 1 shows the slit transcript aligned with a restriction map of the corresponding genomic regions. The known intron/exon boundaries are indicated in Figure 1A and were determined by a comparison of the cDNA sequence with known genomic sequence (Rothberg et al. 1988). The slit cDNA sequence spans a genomic region of $\sim 20 \mathrm{~kb}$ and contains a single 4440 -bp open reading frame (ORF). The nucleotide and deduced amino acid sequences of the ORF are shown in Figure 2. The slit-coding sequence (Codonpreference; Gribskov et al. 1984) starts with a translational start site consistent with the Drosophila consensus (Cavener 1987).

Restriction mapping and sequence analysis of slit cDNA clones revealed two classes of transcripts differing by 33 nucleotides. The location of this sequence variation is shown in Figure 2. The presence of a minor sequence variation prompted a more careful analysis of slit cDNA clones to detect whether other transcript variants existed that might not have been detected by Northern analysis. Utilizing a cDNA screening procedure based on PCR (see Materials and methods), the only detectable size variation was confined to the same region as in the original variant. A comparison of the genomic and cDNA sequences demonstrates that the 33nucleotide size variation is the result of alternate RNA splicing. The two species of slit cDNA differ in the location of a donor $\left(5^{\prime}\right)$ splice site, whereas the acceptor $\left\langle 3^{\prime}\right\rangle$ site is identical.

Our molecular characterization has been extended to include the determination of the site of P-element insertion in four slit alleles (slit ${ }^{F 81}$, slit ${ }^{F 119}$, slit ${ }^{E 158}$, and slit $^{175}$ ), which were recovered during a P-element-based enhancer trap screen (Bellen et al. 1989; Bier et al. 1989).

Figure 1. Transcription unit and molecular characterization of slit P-element enhancer trap alleles. The slit transcript $(A)$ is shown aligned above the corresponding genomic sequence $(B)$. Transcription is shown from left to right. Alternating light and dark shading patterns are used to represent the five $E c o$ RI restriction fragments in the cDNA with the numbers above indicating their size in base pairs. Where known precisely, the locations of splice sites are shown by a connecting "V."

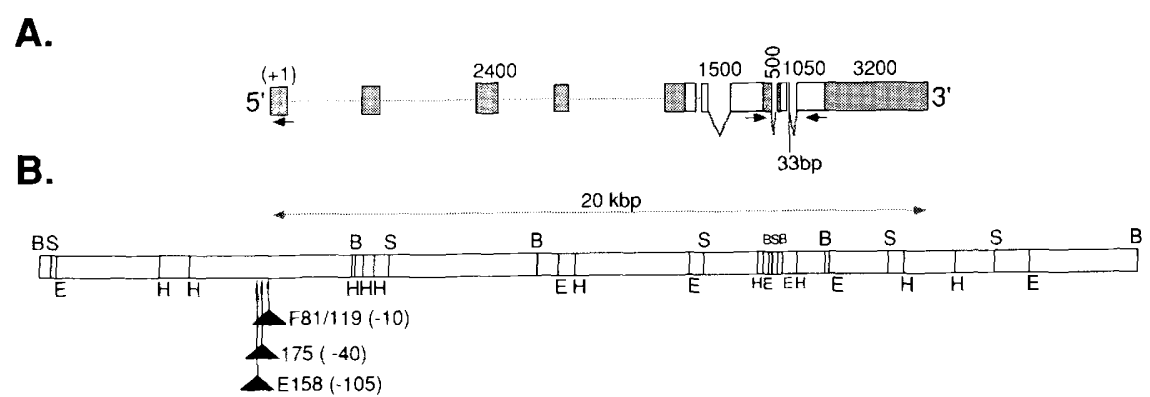
Other exonic regions are shown as blocks aligned approximately with corresponding genomic sequence. The location of primers used to confirm the splice variation in the slit transcript and the resulting 33-bp alternate segment (see text) are indicated by opposing horizontal arrows and a vertical bar, respectively. The location of the primer used to detect the P-element inserts is shown by a left-pointing arrow near the $5^{\prime}$ end of the transcript. (B) A restriction map of the genomic sequence containing the slit transcription unit. Labeled solid triangles indicate the sites of insertion of the enhancer trap construct in the various P-element slit alleles. Their nucleotide positions relative to the consensus transcription initiation site are shown in parentheses. (B) BamHI; (E) EcoRI; (H) HindIII; (S) SalI. 
Genomic DNA from each line was employed in the PCR using primers designed to detect $\mathrm{P}$-element insertions in regions $5^{\prime}$ of the slit-coding sequence (Materials and methods). By direct sequencing of the PCR products, these lines were shown to contain insertions upstream of both the slit consensus transcription initiation sequence and ORF (see Fig. 1B) confirming their initial characterization as slit alleles and suggesting their utility in the characterization of slit expression.

\section{slit Codes for flank-LRR-flank and EGF domains}

The slit transcripts potentially encode two proteins of 1469 and 1480 amino acids, with molecular masses of $\sim 166 \mathrm{kD}$. The predicted initiating methionine is followed by an amino acid sequence containing structural regions characteristic of a secretory signal sequence (Fig. 2). However, hydropathy plots do not predict a transmembrane domain (data not shown). An examination of the slit-coding domain reveals that the majority of the protein is composed of two repeated motifs: the 24 amino acid LRR and the 40-amino acid EGF repeat (Fig. 2). Figure $3 \mathrm{~A}$ shows schematically the positions of these repeats and indicates a higher level of organization among the LRRs. The LRRs are arranged in four groups, each composed of four or five LRRs (Fig. 3B) surrounded by conserved amino- and carboxy-flanking regions (see key in Fig. 3A). The presence of both the LRRs and EGFlike repeats within a single protein make slit unusual; this combination is not found in any other proteins in the NBRF data bank. The absence of any potential transmembrane domains in a sequence having a typical signal sequence and two known extracellular-associated motifs suggests that the slit locus encodes a secreted extracellular protein.

The LRR motif is found in a variety of vertebrate and invertebrate proteins involved in protein-protein interactions (Table 1). Together with their surrounding sequences, the tandem arrays of LRRs in slit form a flankLRR-flank structure, part of which was previously noted in some of the other LRR-containing proteins (Hickey et al. 1989). However, in this analysis, we are extending both the amino-terminal LRR-flanking sequence and the carboxy-terminal flanking sequences to include invariant cysteines, arginines, prolines, and other conserved residues (consensus in Fig. 3C,D). A comparison of other LRR-containing proteins with slit reveals that a subset has homology to slit extending to either one or both of the conserved flanking regions as defined here (Table 1; Fig. 3C,D). This similarity is found in the oligodendrocyte-myelin glycoprotein (OMgp) of humans, the Toll gene of Drosophila melanogaster, and among two sets of structurally related vertebrate proteins involved in adhesive events. OMgp is believed to mediate the adhesion of oligodendrocytes to either other glial cells or axons (Mikol et al. 1990) and contains the amino-flanking region (Fig. 3C) and seven LRRs. Toll, a transmembrane protein, is required for dorsal-ventral pattern formation (Hashimoto et al. 1988) and has an extracellular domain characterized by the presence of two
LRR regions with slit homologous carboxy-flanking sequences (Fig. 3D).

The first set of vertebrate proteins with slit homology in their flanking regions comprise the von Willebrand factor receptor (Titani et al. 1987; Lopez et al. 1988; Hickey et al. 1989). The similarities between slit and two members of this protein complex, GPIX and GPIbß, include the full flank-LRR-flank motif, albeit with a single LRR. The third member of this complex, GPIb $\alpha$, however, contains a tandem array of LRRs and a conserved carboxy-flanking region without a conserved amino-flanking region (Fig. 3D). Extensive similarity between slit and a second group of vertebrate proteins is apparent in their LRR- and amino-flanking regions. This group consists of the extracellular matrix (ECM) proteoglycans decorin (Krusius and Ruoslahti 1986; Day et al. 1987), biglycan (Fisher et al. 1989), and fibromodulin (Oldberg 1989). These proteins have overall homology to one another and define a family of extracellular proteins with conserved amino-flanking regions and 10 consecutive LRRs (Oldberg et al. 1989).

All the proteins exhibiting homology to slit in their LRR-flanking regions have either been shown or are believed to participate in extracellular protein-protein interactions. Moreover, slit contains seven copies of the EGF motif (Figs. 2 and 3A), which also has been shown to participate in extracellular protein-protein interactions (Rothberg et al. 1988). The last EGF repeat is of special interest because the alternate mRNA splicing noted earlier potentially results in the insertion or removal of 11 unique amino acids at the carboxyl terminus of this repeat (see Figs. 2 and $3 \mathrm{~A}$ ).

slit is exported from glial cells and distributed along axon tracts

We have shown previously that slit transcript and protein could be detected at the highest levels in the midline glial cells (Rothberg et al. 1988). However, despite the presence of the slit protein on the axons in the embryonic commissural and longitudinal axon pathways, we failed to detect any transcript or protein in the cell bodies of these neurons. This raised the possibility that the slit protein, which is synthesized in and presumably secreted by the midline cells, can become associated with axons. Here we explore this question further in whole-mount embryo preparations by comparing the sites of slit expression, as assayed by in situ hybridization and the detection of $\beta$-galactosidase in slit enhancer trap lines, with the subsequent localization of the protein as assayed by antibody staining (summarized in Fig. 4).

All four enhancer trap alleles $\mid$ slit $^{F 81}$, slit ${ }^{F 119}$, slit ${ }^{E 158}$, and $s{ }^{175}{ }^{175}$ ) express $\beta$-galactosidase within the ventral midline to varying levels (see Materials and methods). The location of the P-element constructs $5^{\prime}$ of the slitcoding domain, the resulting mutant phenotypes (described below|, and especially their expression patterns are all consistent with their being under the transcriptional control of slit regulatory elements. A summary of 


\section{Rothberg et al.}

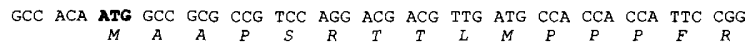
CTC CAG CTG CGG CTA CTG ATA CTA CCC ATC CTG CTA CTC CTG CGC CAT GAT GCG GTC CAC GCG GAA CCG TAT TCC GGC GGA TTC GGC AGC TCA GCT GTA TCC AGC GGT GGA CTG GGG TCA GTG GGC ATT CAC ATA CCC GGC GGC GGA GTG GGC

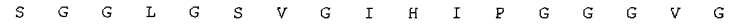

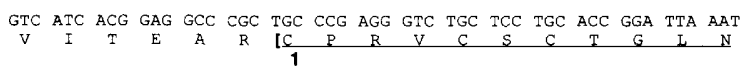

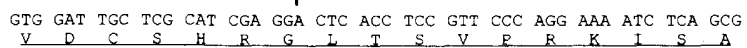
GAC GTG GAG CGA CTC GAG CTG CAG GGA AAC AAT TTG ACC GTG ATA TAC GAG ACG GAT TTC CAG CGG CTG ACC AAG CTG CGA ATG CTC CAA CTA ACT GAC AAT CAG ATC CAC ACG ATC GAG AGG AAC TCC TTC CAA GAT ITG GTC TCA CTC GAG CGA CIG GAC ATC TCC AAC AAT GTC ATC ACG ACC GTG GGT AGA CGC GTC TTS AAG GGA GCC CAA TCG TTG CGG AGT CTI CAG CIG GAC AAT AAC CAA ATC ACC TGC CTG GAT GAG $\triangle A C$ GCC IIT AAG GGA TPG G:G GAG TTG GAG ATA CTO ACS CTG AAC AAC AAC AAC FTG ACT TCC CTG CCG CAC AAC ATC TTC GGC GGA CTI GGA CGT TTG CGG GCA CTC CGG CTG TCG GAC AAT ICG TTC GCC TGC GAC TGC CAP CTG TCC IGG

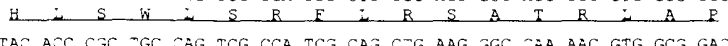

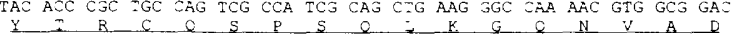

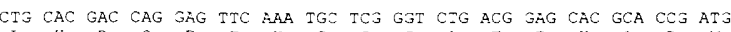
GAA TSC GSG GCG GAG AAC AGC TG: CCS CAC CIA IGT IGC TGT GCG GAC GGJ

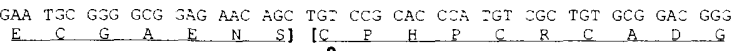

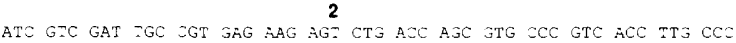
$\therefore \quad \forall \quad P \quad C \quad R$ E K S GAC GAC AOC ACC GAC GTT CGC CTE GAS CAA AAT MTC ATT ACG GAA CTS CCF

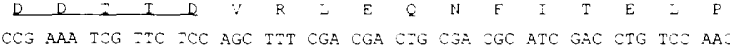
P K S E S S E R R J R R I D E S N

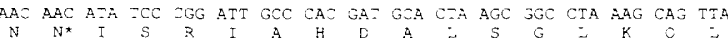
ACE ACT CEC GTG OTG TAC GGC AAP AAA ATA AAG JAT TTA CCE TCG GGE GTS

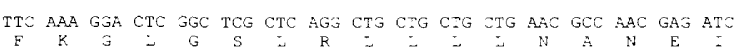
TCS TSC AIA CGC A.G GAT GCC TT: CGE GAC CIG CAC AGT TTG AGC CTS CTO TCE COG TAC GAC ARC AAC ATC CAS TCS CIG GIT AAT GGC ACA TFC GAD GCD

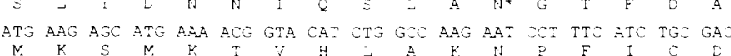

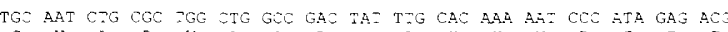
AG: GJA GDC CGC IGC GAG TCA CCG AAG CJG A?G CAT GGT CGT CGG AT? GA

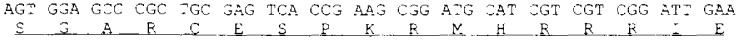
TCS CZG CSC GAG JAG A.RA ITC AAA GG TOC TGG GGT GAR TTG CGG ATS A.A.

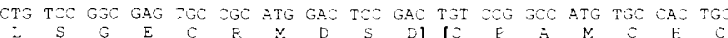

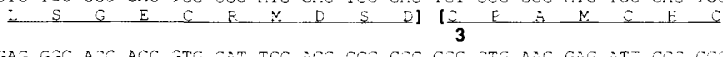

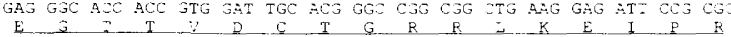
GAC ADT COC CTG CAC ACA ACT GAG CT2 TZG CYC AAC GAC AAC GAA CTG GGA CGE AJC AJT YCC GAT GGC CTC TTE GG: CGC CIG JCG CAC TTG GTG MAS CTJ GAA T?G AAG CGC AAC GAG CTG ACS GGE AIC GAG CCC AAC GCC TPC GAG GGA GCA TOC CAC ATC CAG JAG TTG CAI CTG GJC GAG AAC AAG ATC AAG GAJ ATM A $\underset{T C S}{T A A C}$ AAG ATG TTC ETG GGA CPS CAC CAA CRA AAA ACG CRC AAS CTS TAS GAC AAT CAA ATC ZCA TGC GTT ATS CCC GJT TOC ITT GAG CAT CTC AAC TCT CTS ACG TCG CTG AAC CTC GCA TCG AAT CCA T:C AAT TGC AAT TG? CA: TTS GCO TSG TAC GCG SAA TGC GTG CGO AAA AAA TCA CTG AIC GGC GGA GCA GCA

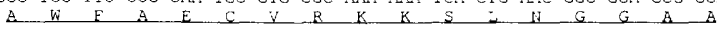

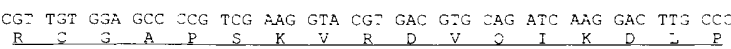
CAC ICG GAA ITC AAG TGT AGC AGC GAS AAC AGC GAG SGC TGC CTG GGO GAT

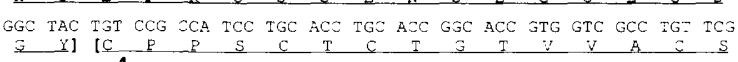
CGT AAC CAG CTG AAG GAG ATA CCG CGA GSC ATT CCC GCC GAA aCA TCS GAJ $R N Q ; K$ E I P B J I E B E I S E

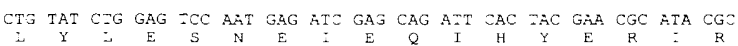

CAT TTG CGC TCC CTT ACC CGA CTC GAT CTC AGC AAC AAC CAG ATC ACC ATT $\underset{I}{C T P}$ TCC AAC TAC ACC TTT GCC AAT CTG ACC AAG CTG TCC ACG CTC ATC ATC TCA TAC AAC AAG CTG CAG TGT CTG CAG CGG CAT GCG TTG TCT GGC CTG AAT

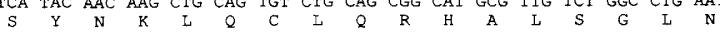
AAC CTG CGC GTC GTT TCG CTG CAC GGT AAC CGC ATC TCG ATG CTG CCG GAA GGC TCC TTC GAG GAC CTC AAG TCG TTG ACC CAC ATC GCA CTA GGC AGC AAT CCC TTG TAC TGC GAC TGC GGT CTA AAG TGG TTC TCC GAT TGG ATC AAG CTG R I Y C D C G I K W F S D W I K I GAC TAC GTG GAA CCG GGA ATT GCA CGT TGC GCC GAA CCG GAA CAG ATG AAG

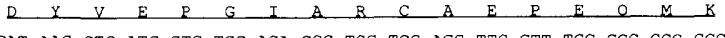
GAT AAG CTG ATC CTG TCC ACA CCC TCG TCG AGC TTC GTT TGC CGC GGC CGC $\underset{V}{G T G}$ CGC AAT GAT ATT CTG GCC AAG TGC AAC GCC TGT TTC GAG CAG CCA TGC

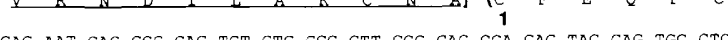

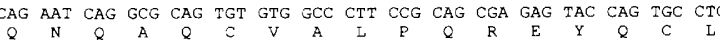

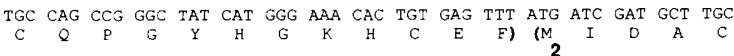
TAC GGA AAT CCG TGC CGC AAC AAT GCC ACC TGC ACG GTG CTG GAG GAG GGT CGA TIC AGC TGT CAG TGC GCT CCG GGA TAC ACA GGT GCC CGC TGC GAG ACG AAT ATC GAC GAT TGC CTG GGC GAG ATC AAG TGC CAS AAC AAT GCC ACC TGC

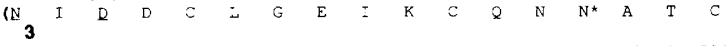
ATC GAC GGA GTS GAG TCG TAC AAA TGT GAG TGC CAG CCG GGA TTC AGT GGC GAG TTC TGC GAC ACC AAA ATC CAG TTC TGC AGT CCG GAG TTC AAT CCC TGC

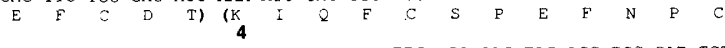
GCG AAI GGA GCO AAG TGC ATG GAC CAC TPIZ ACC CAC TAC AGC TGC GAT TGT CAG GCA GG: TTE CAT GGC ACC AAC TGC ACG GAC AAT APT GAC GAC TGC CAC

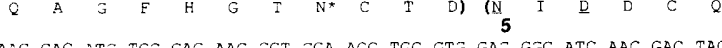
AAC CAC ATS TGC CAG AAC SGT SGA ACG TGC GTS GAD GSC ATC AAC GAC TAC CAA TGC CGE TGT CCA GAC JAC TAT ACG GGC AAG TAC TGT GAA GGC CAC AAC ATG ATE TCG ATG ATG TAT CCA CAG ACS TCG CCT TST CAA AAC CAC GAG TGC Aag CAC GG: GTO TSC TTC CAA SCG AAC GCT CAS GGC AGC GAC TAC CTA TGC AGG TGI CAI CCG GGT TAC ACT GGA AAG TGG TGO GAG TAC CTC ACC AGC ATT

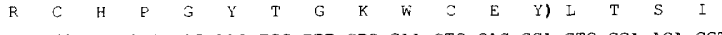
AGC TTC GTS CAC AAC AAC TCG TIT GTG GAA CTS GAG CCA CTG CGA ACA CGT CCG GAG GCS AAC G:G AOG ATA GTC TTC AGC AGE GCS GAG CAG AAT GGA ATT CTC ATG TAE GAE GAC CAG GAT GCA CAT CTC GCA GTJ GAG CTG TPT AAT GGG CGT AT? CGS GTT A.GC TAC GAT GTG GGT RAT CAC CCT GTG TCC ACG ATG TAC AGC TTP GAA ATA GTG GCC GAT GGA AAG TAC CAI GCE GIG GAG CTT CTG GCC ATC AAG AAS AAT TPC ACG OTG CGC GTG GA: CGE GGA TIG GCC CGT TCC ATC

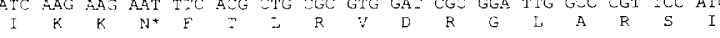
$\underset{\mathrm{I}}{\mathrm{ATC}} \mathrm{AAC}$ GAS GGO TCC AAC GAC ZAC CTG AAA CTP ACS ACT CCC ATG TTC CTG GGC GGC CTA CCA G:G GAT CCT SCA CAG CAG GCA TAC AAG AAC TGG CAA ATA CGC AAC CTP ACC AGC TTT AAG GGC TGC ATG AAG GAS GTG TGG ATC AAT CAT AAG CTG GTE GAC TPT GGC AAT GCC CAG CGC CAG CAA AAG ATC ACA CCA GGA TGT GCC CTG CTE GAA GJA GAG CAG CAA GAG GAS GAA GAC GAC GAG CAG GAT

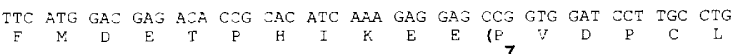
GAG FAC AAA TGS CGT CGG SGC AGT CGC TGT GTS CCS AAT TOC AAT GCC AGG

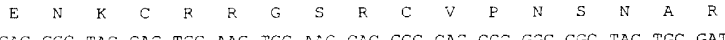
GAC GGC TAC CAS TAC AAG TGC AAG CAC GGC CAS CGC GAC CGC TAC TGC GAT CAA GGT GAG GGC ASC ACT GAG $2 C C$ CCA ACA GTC ACC GCG GCG TCC ACC TGT $\underset{R}{C G C}$ AAG GAS CAG GTG CGC GAG TAC TAC ACG GAS AAC GAC TGT CGC TCG AGG CAG CCG TTS AAG TAC GCC AAG TGC GTG GGC GGC TGC GGC AAC CAG TGC TGC GCG GCC AAA ATT GTG AGA GGG GGC AAG GTG CGC ATS GTG TGC AGC AAC AAC CGC AAG TAC ATE AAG AAC ITG GAC ATC GTG CGS AAG TGC GGA TGC ACC AAG AAA TGO TAC TGA CTG AAA GAT GCG ACT ACC CAA TZG CTC GAA CGG AGC AAT

Figure 2. (See facing page for legend.) 
the embryonic localization of the slit mRNA and protein, and the $\beta$-galactosidase expression of $\operatorname{slit}^{E 158}$ is shown in Figure 4. The expression of $\beta$-galactosidase from the enhancer trap construct in slit ${ }^{E 158}$ shows excellent overall agreement with mRNA localization data at all embryonic stages (Fig. 4, cf. A, D, G, and J with C, F, $\mathrm{I}$, and $\mathrm{L}$. Each method reveals a nearly identical expression pattern starting at gastrulation (Fig. 4A-C). At germ-band extension, all of the midline mesectodermal cells (see Crews et al. 1988; Thomas et al. 1988) show the highest level of slit expression (Fig. 4D-F). During germ-band retraction and nerve cord shortening, expression is most restricted to the six midline glial cells that are derivatives of the midline neuroepithelium (Fig. $4 \mathrm{G}-\mathrm{I}$ ). Localized expression is also evident in the cardioblasts (Fig. 4J-L) during dorsal closure. Figure 5, A and $\mathrm{B}$, shows that the slit protein is most highly localized to the points of contact between opposing pairs of cardioblasts as they coalesce to form the dorsal vessel (presumptive larval heart). All three methods also reveal expression in the walls of the gut (Fig. 4J-L) and in a segmentally reiterated pattern near the muscle attachment sites in the ectoderm (apodemes; Fig. 4G-I). Precise protein localization to the sites where the muscles are attached to the apodemes is seen by confocal microscopy (Fig. 5A,C).

In situ hybridization (Fig. 4D,G, and J) and the expression from the enhancer trap lines (Fig. 4F, I, and L) both support the observation that initially all of the midline cells, and subsequently primarily the six midline glia, are producing slit while lateral neurons are not. However, antibody labeling is seen strongly in the midline glia (Fig. 4E,H) and on the commissural and longitudinal axon tracts (Fig. 4E, $\mathrm{H}$, and $\mathrm{K}$ ) while it is absent from lateral neuronal cell bodies, which supply the bulk of the axons to these bundles. These results suggest that the antibody labeling along the commissural and longitudinal axon tracts is due to the distribution of slit protein exported from the midline glial cells. The protein is also absent from the peripheral nerve roots and peripheral axon tracts.

Immunoelectron microscopy was used to determine the subcellular localization of the slit protein in the ventral nerve cord. Dissected embryonic nerve cords demonstrate staining on the midline cells, as well as on the commissural and longitudinal nerve bundles. Light and electron micrographs of a similarly prepared sample are shown in Figure 6. Although all the derivatives of the neuroepithelium initially express slit, this expression becomes restricted to the midline glial cells during nerve cord condensation and axonal outgrowth. The midline glial cells surround the developing commissural axons, and growth cones have been shown to track along their surface (see Jacobs and Goodman 1989a). Antibody staining can be seen both on the surfaces of the midline glial cells, where they abut growing axons, and on the axons themselves. No detectable variation in the amount of slit staining among subsets of axons or fascicles is detected (see Materials and methods).

We are able to detect slit along the length of the axonal projections in the commissural and longitudinal axon tracts though we are unable to detect any signal above background from the lateral neuronal cell bodies supplying these axons (Fig. 6). Our immunoelectron microscopy demonstrates the extracellular localization of the slit protein and supports the expression data, indicating that the slit protein on the axon tracts is not produced by the neurons whose axons comprise them. Thus, it appears that the axonally distributed slit protein is first secreted from the midline glial cells and then becomes associated with these axons as they traverse the midline.

To obtain direct biochemical evidence that slit is exported from the cells in which it is produced, we investigated slit expression in Drosophila tissue culture cell lines. Schneider line S2 was found to normally express the slit protein, and it can be seen on the surface of a subset of the cells by immunofluorescence /data not shown). Immunoblotting of immunoprecipitated protein extracts from Drosophila embryos and S2 cell lines revealed a single $200-\mathrm{kD}$ band (Fig. 7A, lanes 1 and 2). This size is consistent with expectations of a glycosylated form of the predicted slit protein. Conditioned Schneider cell media (see Materials and methods) also was found to contain a similar 200-kD species (Fig. 7A, lane 3) in addition to two other species that may represent differences in glycosylation (J.M. Rothberg, unpubl.). The presence of the slit protein in the culture media was confirmed by immunoprecipitations of the same molecular mass species from media in which ${ }^{35}$ S metabolically labeled S2 cells had been growing (Fig. 7B). These experiments further support the suggestion that slit is an ex-

Figure 2. The slit nucleotide sequence codes for a putative extracellular protein with both flank-LRR-flank and EGF domains. The cDNA sequence containing the slit-coding region is shown. The coding domain is characterized by the presence of a putative signal sequence (shown in italics) and four distinct blocks of LRRs (numbered and shown in brackets with their characteristic amino- and carboxy-flanking regions underlined), followed by two regions containing EGF-like repeats (numbered and shown in parentheses). The location of the predicted signal sequence cleavage site is indicated by a backslash (von Heijne 1986). Thirteen potential $\mathrm{N}$-linked glycosylation sites are denoted by asterisks $\left({ }^{*}\right)$, and the consensus sequences for $\beta$-hydroxylation (Rees et al. 1988) in the third and fifth EGF repeats are underscored with the possible $\beta$-hydroxy derivative indicated by a double underscore. The 33-bp alternatively spliced segment in the slit transcript and the 11 amino acids that it encodes are shown by a double underline at the end of the seventh EGF repeat. We note the 11 amino acids RCETNIDDCLG found in both the slit (amino acids 981-991) and Delta (amino acids 450-460; Kopczynski et al. 1988) sequences. Numbers correspond to nucleotide positions relative to consensus transciption initiation site and amino acid position relative to first methionine. The nucleotide sequence data for the slit transcript will appear in the EMBL, GenBank and DDBJ nucleotide sequence databases under accession number X53959. 
Rothberg et al.

A.

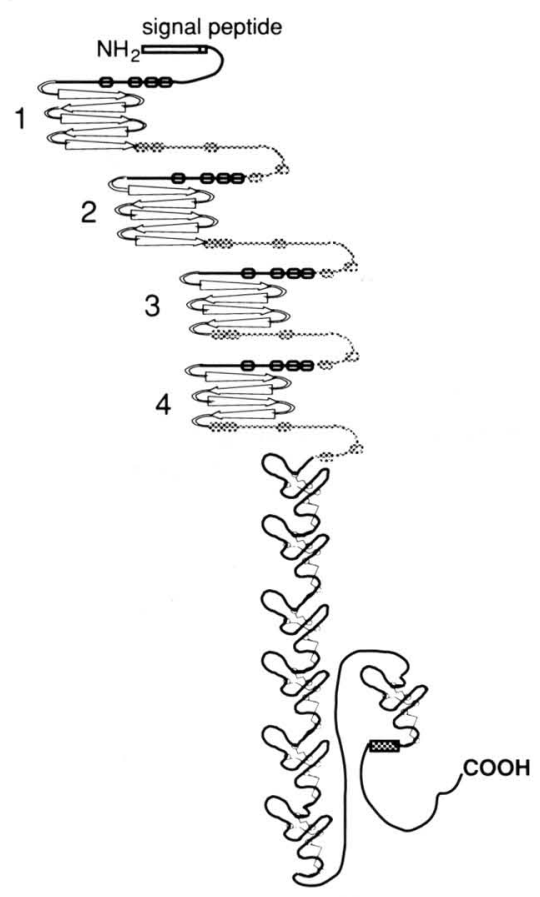

\section{B. slit: Central Leucine-rich Repeat Regions}

\begin{tabular}{|c|c|}
\hline LRRS-1 & 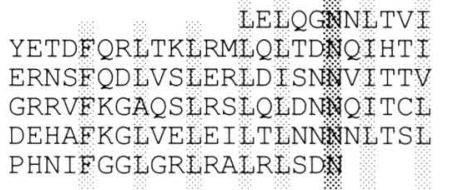 \\
\hline LRRs -2 & 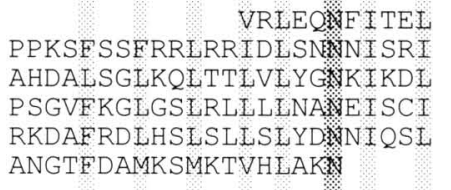 \\
\hline LRRS -3 & 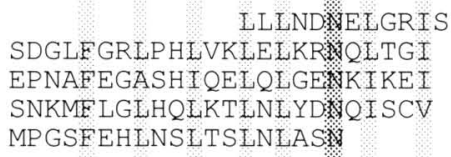 \\
\hline LRRS - 4 & 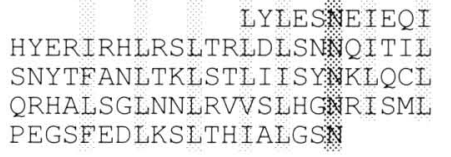 \\
\hline Consensus & $x \times x x F x x \operatorname{Lx} x \operatorname{Lx} x \operatorname{L} x \operatorname{L} x \times N \times I x x L$ \\
\hline
\end{tabular}

\section{Amino-Flanking Regions}

\begin{tabular}{|r|} 
Amino-Flanking Region \\
Leucine-Rich Repeat (LRR) \\
Carboxy-Flanking Region \\
Flank-LRR-Flank
\end{tabular}

\begin{tabular}{|c|c|c|c|}
\hline $\begin{array}{l}\text { slit }-1 \\
\text { slit }-2 \\
\text { slit }-3 \\
\text { slit-4 }\end{array}$ & 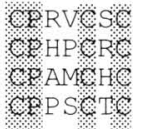 & $\begin{array}{l}\text { TGLNVDV SHRGWT } \\
\text { ADGIVDV REKSW:T } \\
\text { EGTTVDVTGRG.\% } \\
\text { TGTVVAW SRNQWK }\end{array}$ & $\begin{array}{l}\text { SV RKISADVER } \\
\text { SV VVTLPDDTTD } \\
\text { EIORDIPLHTTE } \\
\text { EI RGIPAETSE }\end{array}$ \\
\hline $\begin{array}{l}\text { GPIb } 1 \\
\text { GPIX }\end{array}$ & 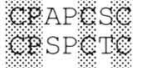 & $\begin{array}{l}\text { AGTLVD } 6 \text { GRRGYTV } \\
\text { RALETMGLWVD }\end{array}$ & $\begin{array}{l}\text { ASL YTAFPVDTTE } \\
\text { A L ALPARTRH }\end{array}$ \\
\hline $\begin{array}{l}\text { Decorin } \\
\text { Biglycan } \\
\text { FM }\end{array}$ & 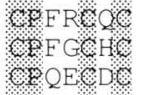 & 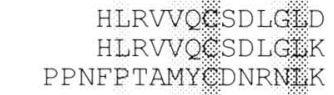 & $\begin{array}{l}\text { KVYKDLPPDTTL } \\
\text { SV KEISPDTTL } \\
\text { YL F FVPRMKY }\end{array}$ \\
\hline OMgp & WLQ L L & TEHRHVDWSGRNA & TLWSGLQENIIH \\
\hline Consensus & \multicolumn{3}{|c|}{ 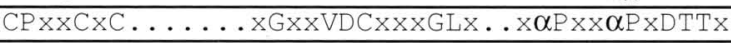 } \\
\hline $\begin{array}{l}\text { LH-CG-R } \\
\text { Chaoptin } \\
\text { GPIb } \alpha\end{array}$ & $\begin{array}{r}\text { CPEPCDC } \\
\text { CTYNVMCI } \\
\text { HPICE }\end{array}$ & $\begin{array}{c}\text { APDGALRCPG } \\
\text { SKSSTDLGIVHCKNVPEP } \\
\text { SKVASHLE VNCDKRNLT }\end{array}$ & $\begin{array}{ll} & \mathrm{P} \\
\text { A } & \text { LPRMVNQSKVP } \\
\text { A } & \text { LPPDLPKDTTI }\end{array}$ \\
\hline
\end{tabular}

\section{Carboxy-Flanking Regions}

\begin{tabular}{|c|c|c|}
\hline $\begin{array}{l}\text { slit }-1 \\
\text { slit }-2 \\
\text { slit }-3 \\
\text { slit }-4\end{array}$ & $\begin{array}{l}\text { SWLSRELRSATRLAPYT } \\
\text { RWLADYLHKIPIETSGA } \\
\text { AWFAECVRKKSLNGGAA } \\
\text { KWESDWIKLDYVEPGIA }\end{array}$ & 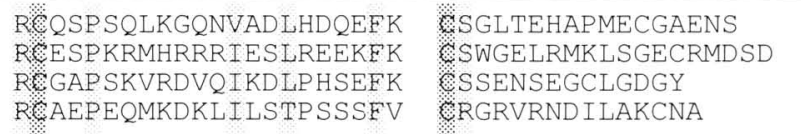 \\
\hline $\begin{array}{l}\text { Toll-1 } \\
\text { Toll-2 }\end{array}$ & 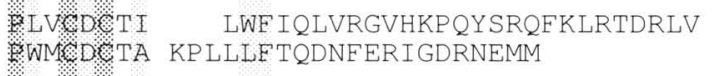 & 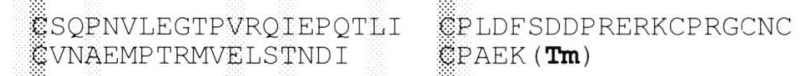 \\
\hline $\begin{array}{l}\text { GPIb } \alpha \\
\text { GPIbß } \\
\text { GPIX }\end{array}$ & 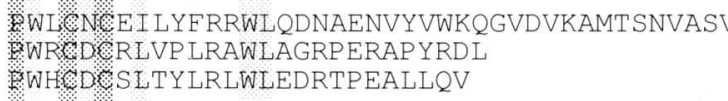 & 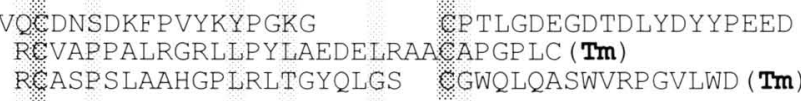 \\
\hline & \multicolumn{2}{|c|}{ 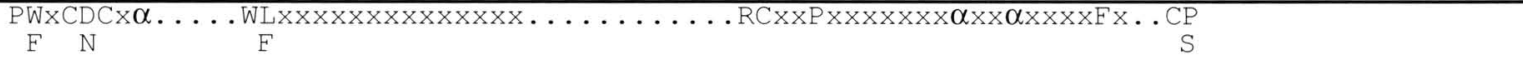 } \\
\hline
\end{tabular}

Figure 3. (See facing page for legend.) 
Table 1. LRR-containing proteins

\begin{tabular}{|c|c|c|c|c|}
\hline Proteins & & Arrangement & Function & Reference \\
\hline Glycoprotein Ib $\alpha$ & & LRR-flank & receptor/adhesion & $\begin{array}{l}\text { Titani et al. }(1987) ; \\
\text { Lopez et al. }(1987)\end{array}$ \\
\hline Glycoprotein Ib $\beta$ & & flank-LRR-flank & receptor/adhesion & Lopez et al. (1988) \\
\hline Glycoprotein IX & & flank-LRR-flank & receptor/adhesion & Hickey et al. (1989) \\
\hline Lutropin-choriogonadotropin receptor & & LRR & receptor & McFarland et al. (1989) \\
\hline $\begin{array}{l}\text { Collagen-binding } 59-\mathrm{kD} \text { protein } \\
\text { (fibromodulin) }\end{array}$ & & flank-LRR & ECM binding & Oldberg et al. (1989) \\
\hline $\begin{array}{l}\text { Small interstitial proteoglycan } \\
\text { PG-S1 (biglycan) }\end{array}$ & & flank-LRR & ECM binding & Fisher et al. (1989) \\
\hline $\begin{array}{l}\text { Small interstitial proteoglycan } \\
\text { PG-S2 (decorin, PG-40) }\end{array}$ & & flank-LRR & ECM binding & $\begin{array}{l}\text { Krusius and Ruoslahti (1986); } \\
\text { Day et al. (1987) }\end{array}$ \\
\hline Adenylate cyclase ${ }^{\mathbf{a}}$ & & LRR & protein-protein & $\begin{array}{l}\text { Kataoka et al. (1985); } \\
\text { Field et al. (1990) }\end{array}$ \\
\hline Ribonuclease/angiogenin inhibitor ${ }^{\mathbf{a}}$ & & LRR & protein-protein & Schneider et al. (1988) \\
\hline Chaoptin & & LRR & homotypic adhesion & $\begin{array}{l}\text { Reinke et al. }(1988) \\
\text { Krantz et al. }(1990)\end{array}$ \\
\hline Leucine-rich $\alpha_{2}$-glycoprotein & & LRR & ?? & Takahashi et al. (1985) \\
\hline Oligodendrocyte-myelin glycoprotein & & flank-LRR & adhesion? & Mikol et al. (1990) \\
\hline Toll & $2 \times$ & LRR-flank & dorsal-ventral polarity ${ }^{\mathbf{b}}$ & Hashimoto et al. (1988) \\
\hline slit & $4 \times$ & flank-LRR-flank & morphogenesis ${ }^{b}$ & this work \\
\hline
\end{tabular}

antracellular proteins; all others are extracellular or cell surface proteins.

${ }^{b}$ Although the role of these proteins in Drosophila development is known, it is not known how their function is mediated.

creted protein. Additionally, immunoblotting of the matrix materials deposited in culture by S2 cells (see Materials and methods) showed the slit protein to be enriched in this fraction (Fig. 7A, lane 4), consistent with the hypothesis that slit functions as an extracellular matrix molecule.

slit mutants exhibit disruptions in midline cells and commissural axon pathways

An analysis of slit null mutant embryos reveals the collapse of the normal scaffold of commissural and longitudinal axons. However, the slit protein is detectable in the midline neuroepithelial cells well before the time of axonal outgrowth (Rothberg et al. 1988). This raised the possibility that the slit protein influences the differentiation of midline cells from the neuroepithelium and that the observed collapse of the axonal scaffold is the result of an earlier developmental abnormality. To examine the development of the midline before axon outgrowth, we followed the fate of the MP2 cells /an identi- fied neuronal precursor cell that normally develops in the most medial row of neuroblasts in the lateral neuroepithelium), as well as the midline neuroepithelium and its progeny (see Materials and methods) in both wild-type and mutant embryos.

In wild-type embryos at the germ-band-extended stage, the MP2 cells are separated by the midline neuroepithelium (Fig. 8A), whereas in slit embryos these cells appear closer together (Fig. 8B). In addition, cell autonomous markers (lines 8-7 and 242) for some of the midline neuroepithelial cells and their progeny (Fig. $8 \mathrm{C}, \mathrm{E}$, and G) are either absent or ectopically expressed before (Fig. 8D) and during axonal outgrowth (Fig. 8F,H). For example, in slit mutant embryos, some of these cells appear absent and others come to lie in an abnormal position along the ventral surface of the nerve cord (Fig. $8 \mathrm{~F}, \mathrm{H})$. These results clearly show a perturbation in the development of the midline neuroepithelial cells as early as the germ-band-extended stage. This disruption further leads to a disruption of their progeny, including the midline glial cells, resulting in a lateral compression

Figure 3. Conservation of flank-LRR-flank domains in known adhesive proteins. (A) Schematic representation of the slit protein. The putative signal sequence and amino- and carboxy-terminal ends of the protein are indicated. The four consecutive flank-LRRflank regions, the seven EGF-like repeats, and the 11-amino-acid connecting segment-the result of differential splicing at the carboxy-terminal of the seventh EGF repeat-are shown (see key). Single LRRs have been shown to form $\beta$-sheets in solution and, as depicted here, may form antiparallel sheets (Krantz and Zipursky 1990). Tandem EGF-like repeats in other ECM proteins have been shown to be arranged in a rod-like conformation and are depicted here as such (see Engel et al. 1989), with the individual EGF repeats modeled after the solution structure of human EGF (Cooke et al. 1987). (B) The amino acid sequence of the 24-amino-acid LRRs comprising the central regions of the flank-LRR-flank structures in slit is presented aligned. Residues identical in $>50 \%$ of the compared LRRs are lightly shaded. Only the asparagine residue $(N)$ (heavily shaded) is found to be invariant. Note the predominance of the aliphatic residues (I, L, V) at the consensus positions. $(C)$ Alignment of the four amino-flanking regions of slit and comparisons with similar regions from other LRR-containing proteins. $(\alpha)$ Aliphatic residues. Sequences preceding the LRRs in other proteins, which show some similarity but do not meet our definition for the amino-flanking region, are shown below the consensus. $(D)$ Carboxy-flanking regions from slit are aligned with corresponding regions from other LRR-containing genes. Flanking regions truncated by transmembrane domains are indicated (Tm). 
of the nerve cord (confirmed by histological analysis; J.R. Jacobs, unpubl.). Given the disruption in the development of the midline of the CNS, the ensuing collapse of the axonal scaffold is not unexpected (see a similar phenotype of the sim mutant; Crews et al. 1988; Thomas et al. 1988).

Mutations caused by the insertion of the enhancer trap P-element allow for a further exploration of the re- lationship between the level of slit expression and the extent of the nerve cord defect. In the wild-type embryo, as observed with antibodies specific to neuronal membranes [anti-horseradish peroxidase (HRP); Jan and Jan 1982], commissural and longitudinal axon pathways appear to form a regular ladder-like structure (Fig. 9A). A wild-type embryo stained with anti-slit antibodies also shows labeling of the CNS axon pathways, as well as

Figure 4. Comparison of in situ, antibody, and enhancer trap staining. The slit message, protein, and promoter activation are visualized at three stages of embryogenesis by in situ hybridization $(A, D, G, I)$, antibody staining $(B, E, H, K)$, and enhancer trap detection $(C, F, I, L)$. The following stages during embryogenesis are shown: gastrulation in a dorsal view $(A-C)$, germ-band-extended stage in a dorsal view $(D-F)$, and nerve cord condensation, from both dorsal $(G-I)$ and sagittal $(J-L)$ views. Staining can be demonstrated by all three methods in the midline neuroepithelium (arrow in $D-F$ ), midline glial cells (bold arrow in $G-K$ ), and cardioblast (open arrow in $(-L)$, as well as in the walls of the gut and in a segmentally reiterated pattern near the muscle attachment sites (thin arrow in $G-I$ ). Note that although no signal above background is detected from the lateral neuronal cell bodies, antibody staining (red arrow in $H$ ) is visible on the axonal projections from these neurons (see also Figs. 6 and 9B).

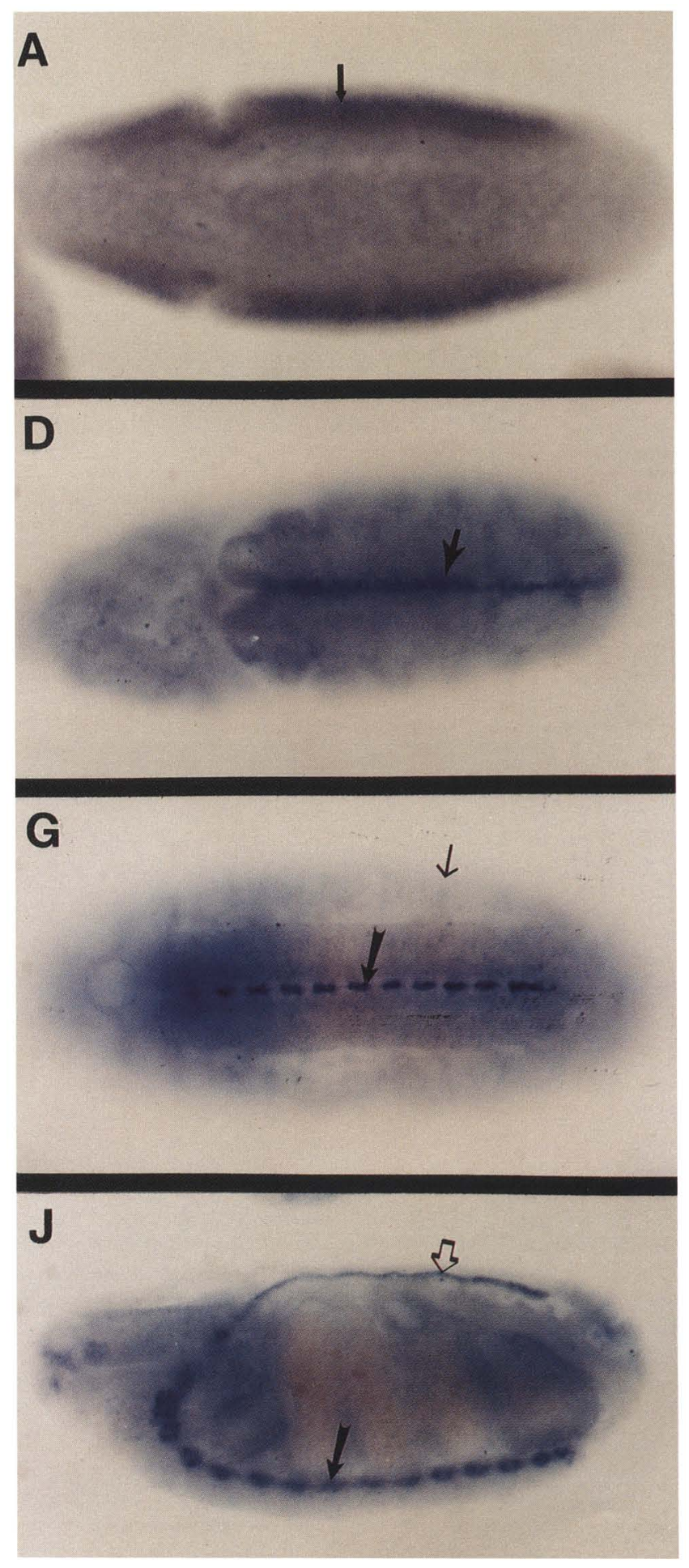


prominent staining of the midline glial cells (Fig. 9B). Embryos homozygous for slit ${ }^{1 G 107}$ do not have any detectable slit expression either in the midline cells or on the axonal bundles (Fig. 9D). This null allele is embryonic lethal; mutant embryos exhibit a lateral compression of the nerve cord (Fig. 9D) and a single fused longitudinal axon tract (Fig. 9C).

As judged by antibody staining intensity in whole- mount embryo preparations, all four enhancer trap slit alleles show reduced levels of slit expression in the homozygous state at $18^{\circ} \mathrm{C}$ and exhibit an intermediate phenotype. Because the P-element construct resides upstream of slit-coding sequences, it is reasonable to assume that it is not the disruption of the slit protein per se that is responsible for the observed mutant phenotypes but, rather, a reduction in the level of slit expres-

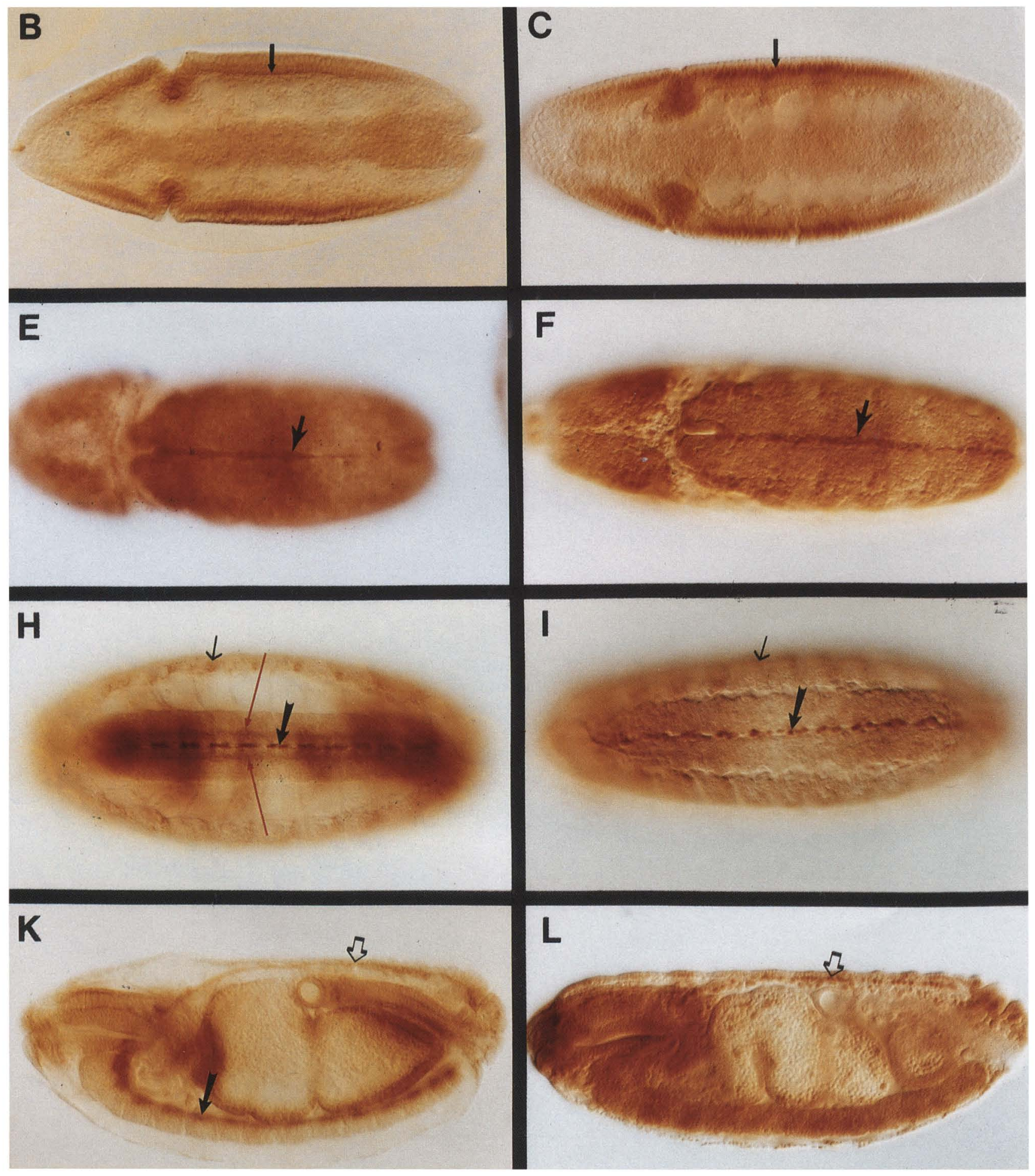


Rothberg et al.

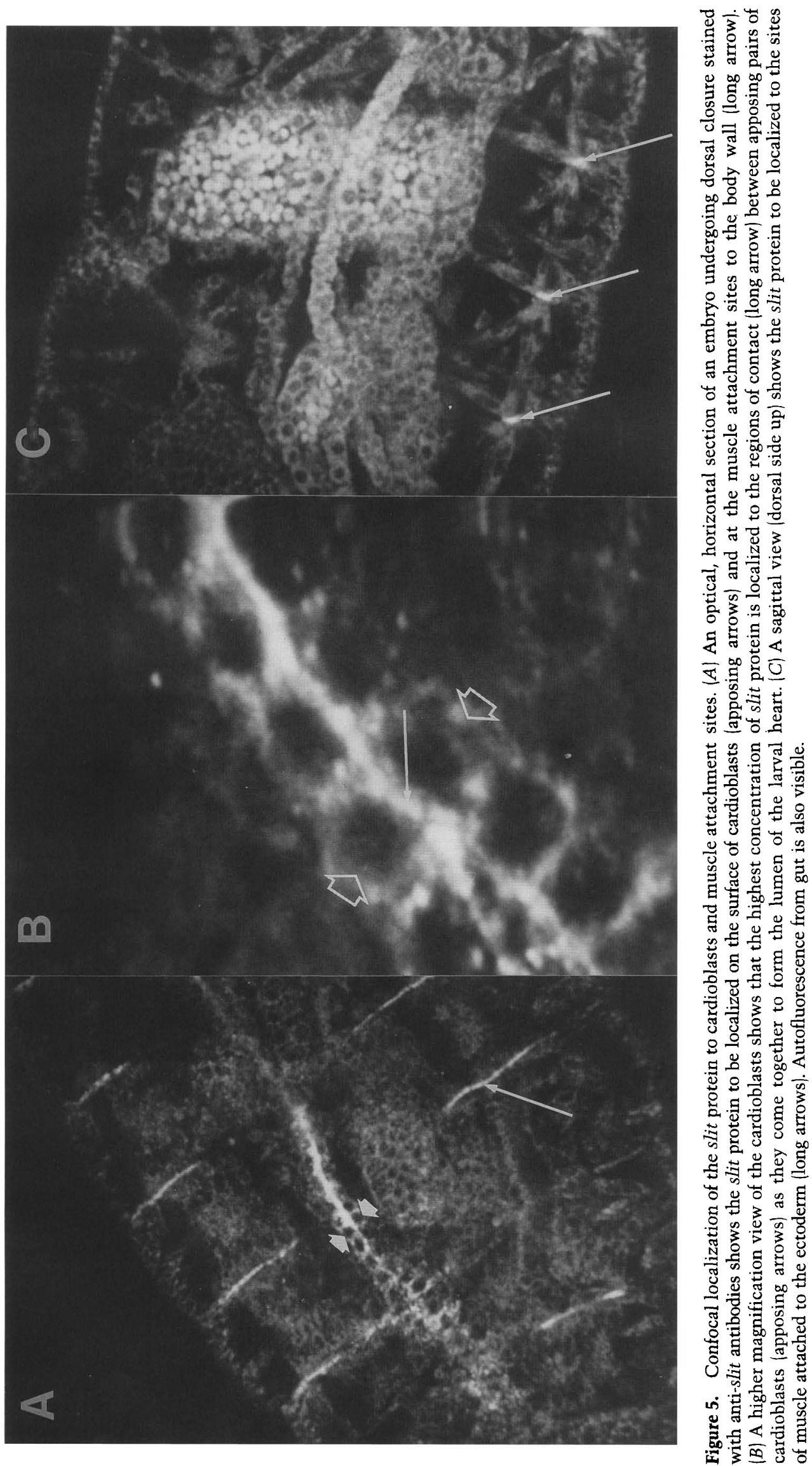




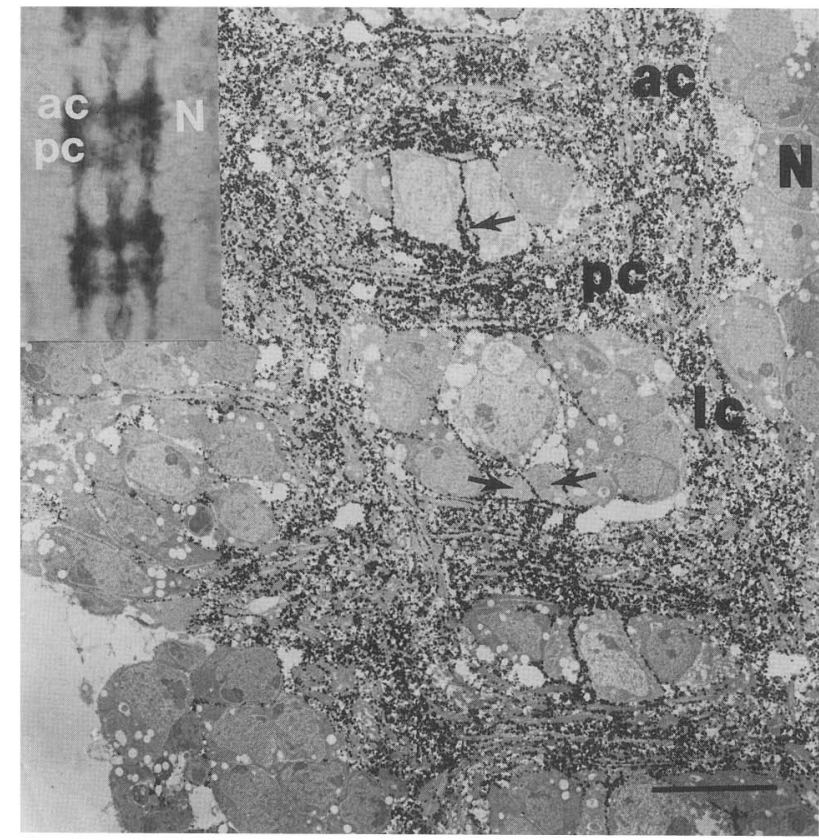

Figure 6. Immunoelectron microscopic localization of slit in the embryonic CNS to midline cells and axonal tracts. Staining with anti-slit antibody in a frontal section through the plane of the longitudinal and commissural axonal tracts, detected by silver intensification of an HRP-conjugated secondary antibody. At the electron microscopic level, labeling is both on the axons comprising the longitudinal connectives (lc), anterior (ac) and posterior (pc) commissures, and on the cells lying between them including the processes of the midline glial cells (arrows). A light level frontal view of a similarly prepared dissected nerve cord shows strong axonal labeling with respect to the midline cells (insert). No signal above background is seen on lateral neuronal cell bodies $(N)$, either at the light or electron microscopic level. Bar, $5 \mu \mathrm{m}$.

sion. These mutations are embryonic and larval lethals and, in contrast to the null allele slit ${ }^{I G 107}$, exhibit only partial compression of the midline and a concomitant partial collapse of the axonal scaffold (Fig. 9E,F). We note variable levels of slit expression in the midline cells, often at lower levels and in a more diffuse pattern compared to wild type. This variability is seen both between individual embryos and between segments in the same embryo (Fig. 9F). The segments with the lowest levels of expression exhibit the least differentiation of their midline cells, including their midline glia, and show the greatest degree of collapse of both the ventral nerve cord and the axon tracts (Fig. 9F). Segments exhibiting higher levels of expression appear at a gross level to have nearly normal midline glial cells, commissures, and longitudinal axon tracts (Fig. 9F).

\section{Discussion}

It has long been thought that the extracellular environment influences the regulation of gene expression and the morphogenesis of cells during embryonic development (see McDonald 1989). In the nervous system, the morphogenetic events accompanying the formation of early structures have been shown to be dependent on the properties of the molecules that form their extracellular environment (see Jessell 1988). In vitro and in vivo studies suggest that growth cone guidance and axonal pathway selection are influenced by adhesive interactions between axons and ECM molecules /see Sanes 1989). Furthermore, specific constituents of the extracellular environment have been shown to affect neurite outgrowth in vitro and have been detected in vivo in the developing central and peripheral nervous systems (see Rutishauser 1989).

In this paper we show that the slit locus, whose mutant phenotypes indicate that it plays a major role in the development of the specialized midline glial cells and the commissural axon tracts that traverse them, encodes a unique extracellular protein containing two structural motifs associated with adhesive interactions. The slit protein has four regions containing tandem arrays of a 24-amino-acid leucine-rich repeat with conserved flanking sequences (flank-LRR-flank) and two regions with EGF-like repeats. Although the LRR and EGF motifs are not found together in any other proteins in the NBRF data bank, each has been found in conjunction with other sequence motifs, often forming a distinct region of a larger protein involved in protein-protein interactions. As part of larger proteins, each of these

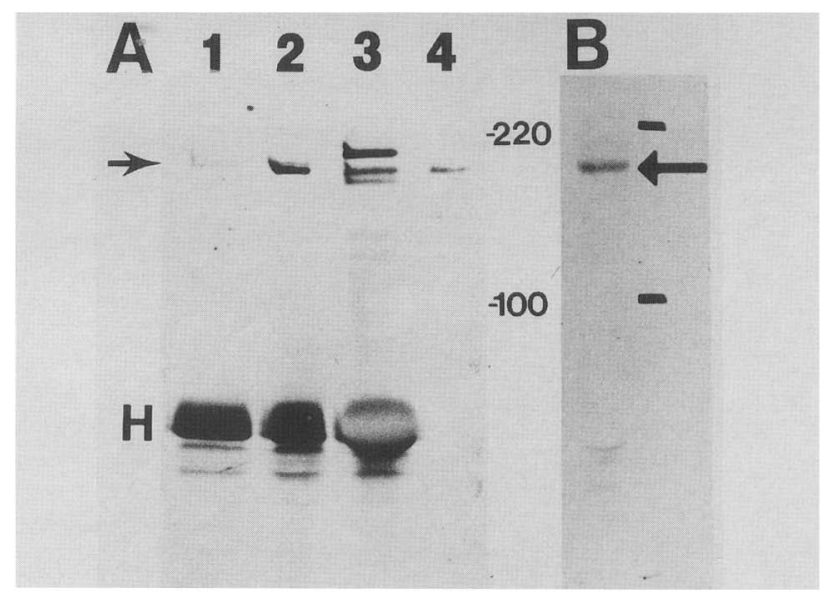

Figure 7. Secretion of slit from cultured cells. $|A|$ An immunoblot with anti-slit antibodies of slit protein immunoprecipitated from embryos (lane 1) and S2 culture cells (lane 2) shows a common protein species of $\sim 200 \mathrm{kD}$ (arrow). This species is also immunoprecipitated from S2 cell line-conditioned media (lane 3), indicating that the slit protein can be exported from the cells in which it is produced (see text for discussion). (Lane 4) By immunoblotting, the $200-\mathrm{kD}$ slit protein species can also be detected in the matrix materials deposited by the S2 cells in culture (see Materials and methods). The predominant band seen in immunoprecipitations is immunoglobulin heavy chain $(\mathrm{H}) .(B)$ The media in which ${ }^{35} \mathrm{~S}$ metabolically labeled S2 cells had been cultured were immunoprecipitated with anti-slit antibodies, separated by SDS-PAGE, and detected by autoradiography. Consistent with the immunoblotting results, a major $200-\mathrm{kD}$ species is detected (arrow). Tick marks indicate position of $100-$ and $220-\mathrm{kD}$ size standards. 
Rothberg et al.

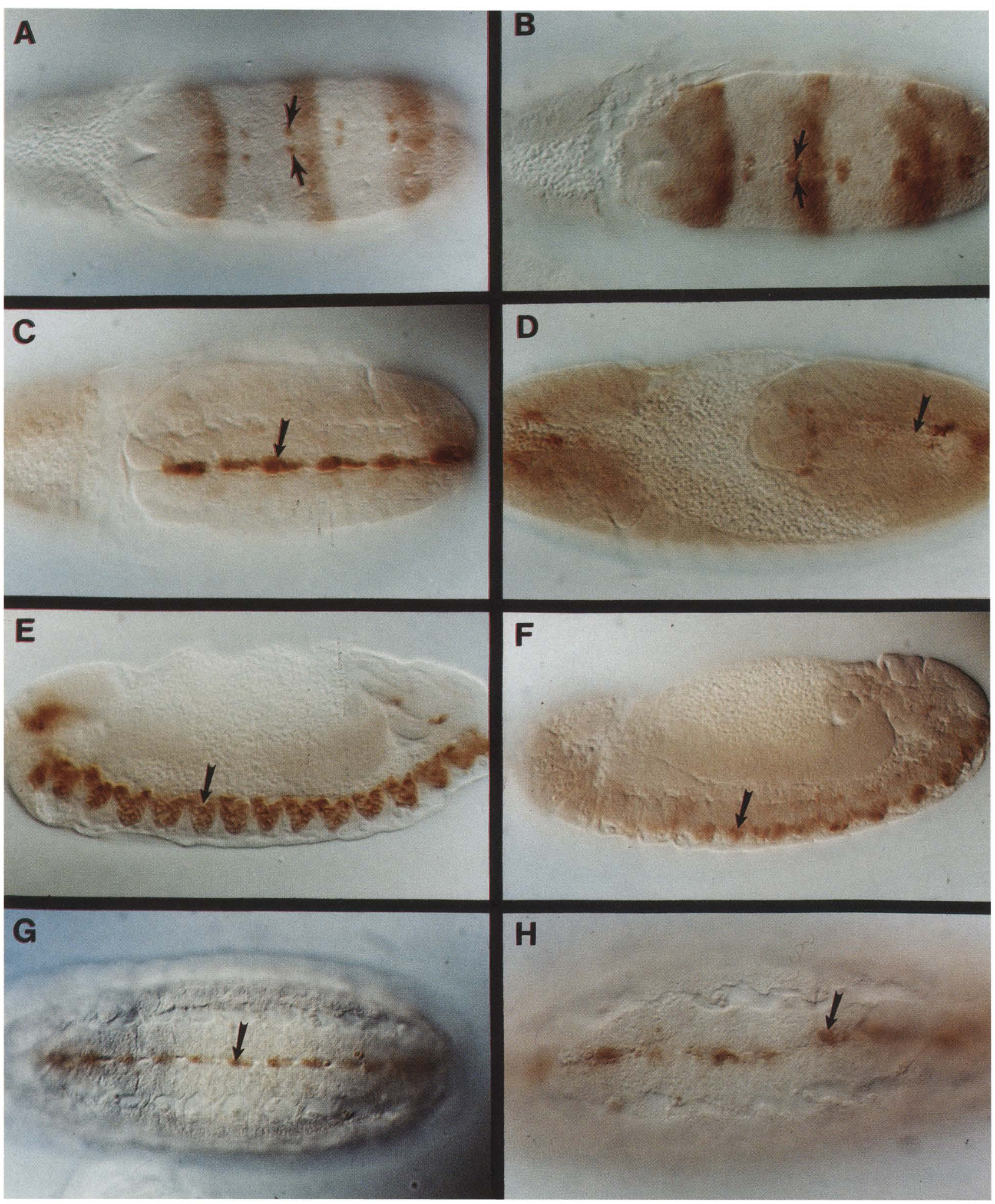

Figure 8. (See facing page for legend.) 
motifs has been shown to contribute directly to these interactions.

The LRRs in slit are similar to those that were first identified in human leucine-rich $\alpha_{2}$-glycoprotein and later in a variety of vertebrate and invertebrate proteins involved in protein-protein interactions, both inside and outside the cell (Table 1). In the extracellular environment, the LRRs have been found in conjunction with a variety of conserved protein motifs (McFarland et al. 1989; Mikol et al. 1990). Of greatest interest to us, however, is the fact that the LRRs in extracellular proteins are often found accompanied by either one or both of the conserved amino- and carboxy-flanking regions identified in the slit protein (see Table 1). In all of the cases where the LRRs are accompanied by these flanking regions, the proteins have either been shown, or are believed, to participate in extracellular adhesive interactions. Although we do not yet know the significance of the individual flanking regions in these interactions, a functional role for at least the carboxy-flanking sequence has been demonstrated in vivo: Mutations in the cysteines of this region in the Drosophila Toll protein confer a dominant phenotype (K. Anderson, pers. comm.).

In addition to Toll and the OMgp, two distinct families of adhesive proteins have slit homology extending to the LRR-flanking sequences. The first includes a set of functionally related interstitial proteoglycans known to bind directly to ECM proteins: biglycan, fibromodulin and decorin. Biglycan binds laminin and fibronectin (A. Skubitz, pers. comm.) while fibromodulin, and decorin bind collagen and fibronectin and have a regulatory effect on collagen fibril formation (Vogel et al. 1984; Schmidt et al. 1987; Hedbom and Heinegård 1989; Oldberg et al. 1989). The second set comprises the proteins of the glycoprotein Ib-IX (GPIb-IX) complex, which together function as a receptor for the von Willebrand factor (vWF) and thrombin and are responsible for vWFdependent platelet to blood vessel adhesion. In this complex, the LRR-containing region of the GPIb $\alpha$ chain binds one of a set of three repeated 200-amino-acid sequences termed A domains in vWF (Mohri et al. 1988; Titani et al. 1987). In addition to demonstrating the role of the LRR motif in protein-protein interactions, this homology also raises the possibility that similar regions in slit might bind to proteins containing repeats homol- ogous to the A domains of vWF. In vertebrates, these proteins include both ECM molecules and integrins (see Larson et al. 1989).

The conservation of the amino-terminal sequences flanking a LRR region in a family of proteins that participate in direct adhesion to ECM components suggests that this structure may play a similar role in slit. Alternatively, the conservation of the entire flank-LRR-flank motif in slit and the GPIb-IX complex offers the intriguing possibility that the interactions of slit with the ECM, like that of the vWF and thrombin receptor, could be mediated by additional factors.

In comparing the various proteins known to contain the EGF-like motif, it is clear that this sequence is always found in an extracellular environment; and in many instances, these sequences have either been implicated or shown to function directly in protein-protein interactions (Appella et al. 1988). In addition, these repeats are found in conjunction with a variety of other structural and catalytic domains in molecules invólved in blood coagulation (see Furie and Furie 1988) and in adhesive ECM glycoproteins (see Engel 1989). Tandem arrays of EGF-like repeats comprise the majority of the extracellular domains of the cell-surface proteins Notch (Wharton et al. 1985) and Delta (Vassin et al. 1987; Kopczynski et al. 1988) and have been implicated in $\mathrm{Ca}^{2+}$-dependent heterotypic adhesive interactions between the two proteins as well as in homotypic interactions in the Delta protein (Fehon et al. 1990).

The EGF-like repeats in slit are arranged in two groups in a fashion similar to the arrangement found in cellsurface and extracellular adhesive proteins and in EGFlike ligands, respectively (see Appella et al. 1988; Lander 1989). An additional similarity between the EGF-like repeats in slit, Delta, and Notch is a conserved recognition site for a post-translational modification involved in $\mathrm{Ca}^{2+}$ binding (Rees et al. 1988) and a consensus sequence implicated in $\mathrm{Ca}^{2+}$-dependent protein-protein interactions (Handford et al. 1990). By these criteria, the third and fifth EGF-like repeats of slit are potential candidates for $\beta$-hydroxylation and may participate in $\mathrm{Ca}^{2+}$-dependent interactions. The seventh and last EGF domain in slit is separated from the tandemly arranged EGF-like repeats by 202 amino acids. It will be of interest to determine whether the alternate splicing variant seen in slit, which results in a change of coding capacity at the

Figure 8. Null mutant embryos exhibit disruptions in midline cells. The pattern of expression of $\beta$-galactosidase in MP2 cells $(A$ and $B$ ) and the midline neuroepithelium and its progeny $(C-H)$ is compared in wild-type and null mutant embryos (see Materials and methods). Anterior is toward the left. (A and $B)$ A dorsal view shows the MP2 cells (arrows) well separated by cells of the midline neuroepithelium at the extended germ-band stage in wild-type embryos $(A)$ but closer together in a slit mutant background $(B)$, indicating an early disruption along the midline. $(C$ and $D)$ The midline neuroepithelium at the germ-band-extended stage (arrow in $C$ ) and its midline progeny $(E$ and $G)$ are clearly labeled in wild-type embyros. In comparison, following germ-band extension in slit mutant embryos there is either no midline neuroepithelial labeling or low levels of labeling slightly later (arrow in $D)$. $(E$ and $F)$ A sagittal view during nerve cord condensation shows the bulk of the midline cells of each neuromere clearly expressing $\beta$-galactosidase in the wild-type embryo (arrow in E). However, in slit mutant embryos, the expressing cells are reduced in number and displaced to the ventral edge of the nerve cord (arrow in $F)$. $(G$ and $H$ ) A dorsal view of a similarly staged wild-type $(G)$ and slit mutant $(H)$ embryo. In the wild type the midline cells can be seen in the space separating adjacent neuromeres within a segment. In slit mutant embryos, expressing cells can be seen to lie irregularly shifted laterally, as well as ventrally (arrow). 


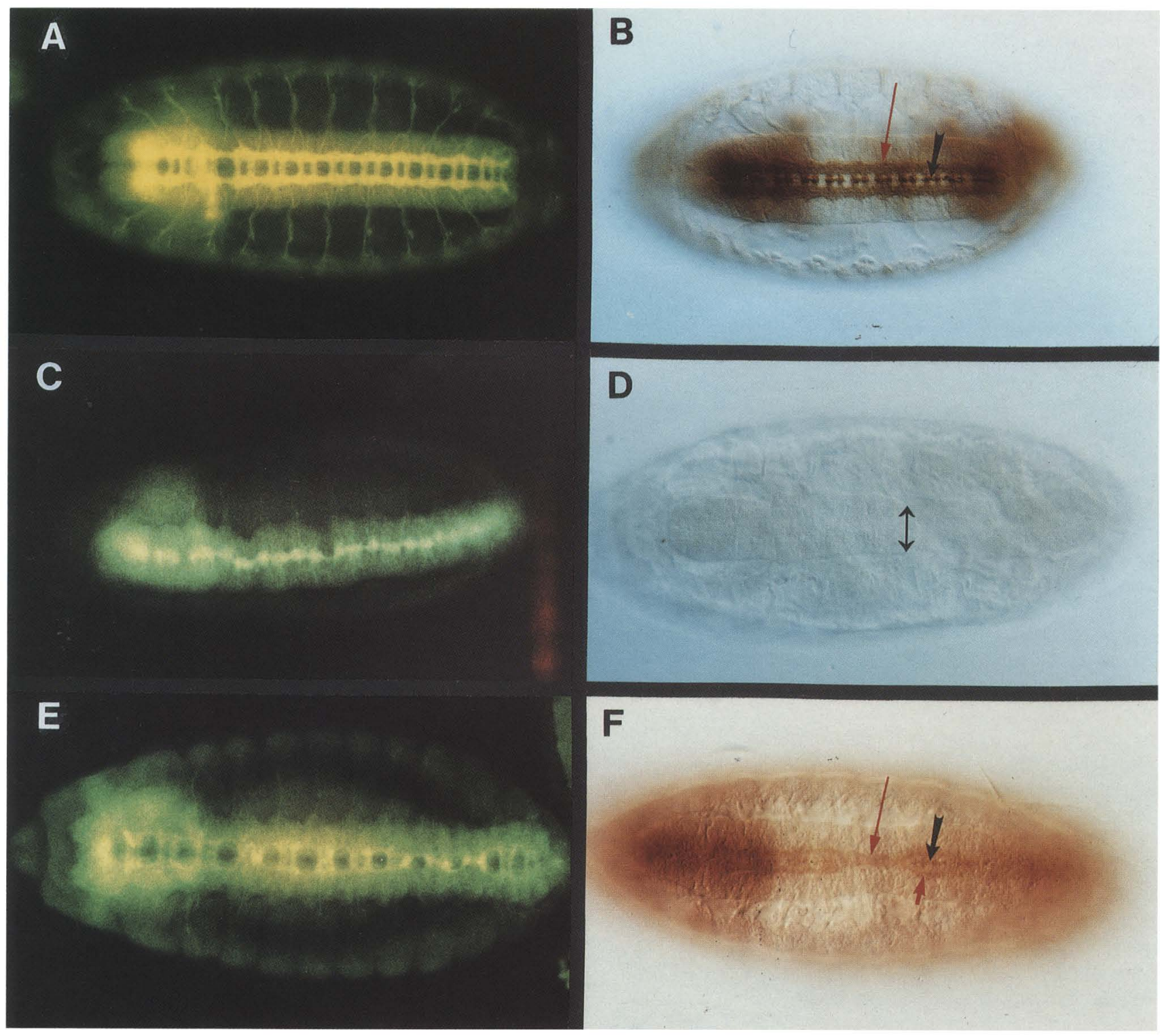

Figure 9. Levels of slit expression correlate with disruptions of midline cells and axon pathways. The major axonal pathways are labeled with anti-HRP antibodies $(A, C$, and $E)$ (Jan and Jan 1982) and compared to the staining pattern seen with antibodies against the slit protein $(B, D$, and $F)$. In these horizontal views, anterior is toward the left. $(A$ and $B \mid$ In wild-type embyros the ladder-like arrangement formed by the commissural and longitudinal axonal tracts is visible. Staining with antibodies against the slit protein $(B)$ shows labeling of the midline glial cells (black arrow), as well as axonal staining (red arrow). ( $C$ and $D)$ Anti-HRP stained null mutant embryos $(C)$ exhibit a single centrally located longitudinal nerve bundle along the length of the CNS. No detectable slit staining is seen $(D)$. The lateral neuronal bodies are shifted inward toward the center, filling the space normally occupied by the midline cells. An overall reduction in the width of the nerve cord is also observed (double-ended arrow). ( $E$ and $F)$ slit ${ }^{E 158}$ mutants exhibit an intermediate phenotype characterized by a partial collapse of the axonal scaffold. Relatively weak slit staining is visible along the length of the axonal bundles $(F)$. Segments with the highest levels of slit staining (black arrow), have more midline cells and a less severe collapse of the longitudinal connectives (short red arrow) in comparison to segments with lower expression levels (long red arrow). Segments with reduced levels of slit expression exhibit nerve cord compression and a concomitant fusion of the axon tracts (long red arrow).

carboxyl terminus of this EGF-like repeat, provides for a unique functional constituent of the protein with altered binding specificity.

\section{Export and cell binding}

Using both whole-mount in situ hybridization and slit enhancer trap alleles, we are able to demonstrate that slit is produced in the developing midline neuroepithelium, as well as in its progeny midline glial cells along the dorsal midline of the CNS but not in the neuronal cell bodies whose axons form the major commissural and longitudinal axon tracts in the CNS. Light and immunoelectron microscopy indicate that slit is exported from the midline glial cells and is associated with the axons that traverse them. If, as is suggested by these 
data, the slit gene product is not produced in the neurons of the axons on which it resides, we expect that it is secreted from the midline cells and "picked up" by passing axons. This, in turn, raises the possibility that the axons that carry slit on their surface may be expressing specific receptors capable of interacting with slit in a direct or indirect manner. An analysis of slit expression in Drosophila cell culture demonstrates that slit can be localized to the surface of individual cells. Additional biochemical support for the extracellular, secreted nature of the protein was provided by demonstrating that tissue culture cells producing slit are secreting the protein into the media. Moreover, consistent with the hypothesis that slit functions as an ECM molecule, we found the protein to be accumulated in the matrix materials deposited by these cells.

\section{Morphogenetic regulation of the neuroepithelium}

A model for slit function wherein it regulates the morphological differentiation of a cell by attaching to both the ECM and cell-surface receptors is consistent with its predicted structure, expression pattern, and phenotype. Like the other ECM glycoproteins, slit is composed of repetitive structural motifs and lacks the hydrophilic regions characteristic of membrane-spanning cell-surface adhesion molecules. ECM glycoproteins play a diverse role in development, acting as signals for cell differentiation, growth, and migration. Furthermore, the slit-homologous proteoglycan decorin is involved in the control of cell proliferation and has the ability to convert transformed cells to morphological regularity (Yamaguchi and Ruoslahti 1988).

Here we demonstrate the involvement of slit in the development and differentiation of the midline neuroepithelium and the subsequent formation of commissural axon pathways. In a slit mutant background the midline cells do not undergo proper differentiation or morphological movements; instead of filling the midline of each neuromere as they do in the wild-type embryo, they appear at the base of the nerve cord and are fewer in number. This is followed by the complete collapse of the axonal scaffold. The in vivo effects of reductions in slit expression further indicate that the morphogenesis of the midline cells and the subsequent axonal pathway formation are dependent on the concentration of slit protein. Using P-element-induced slit alleles, we are able to demonstrate that a reduction in slit expression is coincident with the lack of development of the midline cells of an individual segment and specifically, with the development of the midline glial cells. We show further that the variability in the extent of collapse of the midline of the nerve cord is mirrored by the extent of collapse of the commissural and longitudinal axon pathways.

We note with interest that the extent of disruption in the ventral nerve cord in slit alleles corresponds to the range of phenotypes exhibited by mutations of the Drosophila EGF-like receptor homolog (DER). Given the homology between slit and EGF-receptor ligands, the colo- calization of the DER and slit proteins to the midline glial cells and the muscle attachment sites (Zak et al. 1990) raises the possibility that slit functions as a DER ligand. This speculation is particularly attractive, as the activation of a receptor tyrosine kinase by the slit protein would offer a mechanistic explanation for the influence of slit on either the development or maintenance of the midline cells and provide for a direct molecular link between the ECM and genes involved in cellular proliferation and differentiation (see Yarden and Ullrich 1988).

\section{Implications of slit expression}

The three major regions of slit expression are the midline neuroepithelium of the CNS, the attachment sites of muscle to epidermis, and the cardioblasts of the dorsal tube. The expression of slit in the cardioblasts as they meet and form the lumen of the dorsal tube may be of general interest given that in vertebrate tissue culture, the ECM has been shown to be involved in endothelial cell alignment and the induction of capillary tube formation (see Ingber and Folkman 1989). This process is one of the best characterized morphogenetic processes in vitro and has allowed for an analysis of the molecular mechanisms by which ECM molecules, specifically collagen, laminin, and fibronectin, are able to control capillary morphogenesis (Grant et al. 1989).

In Drosophila, the larval heart or dorsal vessel is derived from two longitudinal rows of mesodermal cells termed cardioblasts. When these cells meet following dorsal closure along the midline, only their dorsomedial and ventromedial surfaces contact, with the space between forming the lumen of the dorsal vessel (Poulson 1950; Hartenstein and Campos-Ortega 1985). slit is expressed in the developing cardioblasts during the time they come together. Confocal microscopic imaging clearly shows the slit protein to be concentrated at the point of contact between the cardioblasts as they come together and form the lumen of the larval heart. Given the unique structural characteristics of slit, its homology to ECM-binding proteins, and the role of these ECM proteins in vessel formation, an analysis of the role of slit in developing cardioblasts and its possible interactions with other proteins expressed in these tissues during larval heart formation may serve as a useful in vivo model for the study of the angiogenic process.

Confocal microscopy shows the slit protein to be tightly localized to the points of muscle attachment to the epidermis. This localization is consistent with slit functioning as an ECM molecule and suggests its involvement in adhesive events. The muscle attachment sites are known sites of ECM deposition (Newman and Wright 1981), and the position-specific integrins have been shown to be localized here (Leptin et al. 1989). Hence, a role for slit in adhesive-mediated events such as muscle attachment and axonal outgrowth is supported both by its structure and its expression pattern. The potential for two variants of the slit protein raises the possibility that these roles are mediated by functionally distinct forms of the protein. 
Tissue culture studies have demonstrated that growth cones adhere to and extend neurites onto ECM molecules such as laminin and fibronectin (see Sanes 1989) and that the direction and rate of axonal growth are dependent on these axon-matrix interactions (see Rutishauser and Jessell 1988). Given the homology of slit to the laminin-binding protein biglycan, we note with interest that laminin is expressed on glial surfaces and along the pathways axons follow in the establishment of the commissural and longitudinal axonal tracts in Drosophila (Montell and Goodman 1989).

The possibility that slit binds to matrix materials suggests that its presence on growing axons could influence their interactions with ECM proteins. The ability of axons to fasciculate on one another in all slit mutants indicates that slit is not necessary for axon-axon fasciculation. However, the combination of flank-LRR-flank, tandem EGF, and single EGF motifs in a protein with the unique embryonic distribution of slit could allow for the formation of a "molecular bridge" between axonally associated receptors and ECM molecules. Prompted by the information on the structure of slit, its expression in glial cells, and its presence on axons that extend along these cells, we propose a testable, hypothetical mechanism whereby glial cells can influence the future behavior of an axon: (1) Glial cells secrete multifunctional molecules which have the ability to attach to specific axonal receptors, as well as to specific ECM components into the endoneural basal lamina; (2) passing axons carrying receptors for these proteins pick them up from the glial cell surroundings; and (3) depending on the proteins associated with them, axons are able to respond to cues and interact with molecules in the ECM.

\section{Materials and methods}

\section{Drosophila stocks and genetics}

slit ${ }^{F 1}$ and slit $^{F 119}$ were created by germ-line transformation with the enhancer trap construct P-lacW (Bier et al. 1989) and slit ${ }^{E 158}$ was made using P-lArB (gifts of A. Kolodkin; Bellen et al. 1989|. Other slit alleles are as described in Rothberg et al. (1988). slit ${ }^{175}$ exhibits some ectopic $\beta$-galactosidase expression, whereas $\operatorname{slit}^{F 81}$ and $\operatorname{slit}^{F 119}$ (likely the result of the same insertion event) have levels of midline expression lower than levels in slit ${ }^{E 158}$. Lines 8-7 and 242 function as cell autonomous markers for the midline neuroepithelium and contain the PZ and $\mathrm{HZ}$ enhancer trap constructs that use the P-element and $\mathrm{ftz}$ promoters, respectively, to drive $\beta$-galactosidase expression (a gift of Y. Hiromi). Line 5704 expresses $\beta$-galactosidase from the $f t z$ promoter in MP2 cells (Hiromi et al. 1985). Lines 8-7, 242, and 5704 were made homozygous in slit $^{i G 107 / C y O}$ flies to characterize the development of the midline in slit $^{I G 107} /$ slit $^{I G 107}$ embryos.

\section{Isolation of cDNA and genomic clones}

Isolation of the initial slit cDNA clones was described in Rothberg et al. (1988). Both PCR (Saiki et al. 1988) and standard library screening methods (Maniatis et al. 1982) were employed to extend this analysis. A cDNA clone representing the $5^{\prime}$-most $2.4 \mathrm{~kb}$ of sequence (ka2.4) was isolated from the larval library of
Poole et al. (1985), and PCR was used to isolate a corresponding sequence (be2.4) from a 4- to 8-hr embryonic library (Brown and Kafatos 1988). Two forms of the slit message differing by 33 nucleotides were evident when restriction fragments from the larger class (B52-1 and B52-2) were compared with those from the smaller class (B52-5). Primer pairs covering adjacent segments of the coding region were utilized in the PCR to screen embryonic cDNA libraries (Poole et al. 1985; Brown and Kafatos 1988) for the presence of multiple cDNA forms. One class already represented by B52-1 and B52-2, and one by B52-5 were generated. Genomic and cDNA sequencing indicates the transcripts consist of a $\sim 314$-bp 5 '-untranslated leader sequence, followed by either a 4407- or 4440-bp ORF, depending on the splice form, and a $\sim 4-\mathrm{kb}$ untranslated 3 ' end. EcoRI cDNA fragments representing the entire transcription unit were aligned with genomic sequences by Southern analysis.

\section{Subcloning, sequencing, and localization of P-element insertion sites}

The relevant regions from phage, plasmid, and PCR-generated cDNAs were subcloned into Bluescript (Stratagene) or M13mp18/19 vector. Single-stranded templates were sequenced directly or subjected to deletions by T4 polymerase (International Biotechnologies). Chain termination sequencing (Sanger et al. 1977) used Sequenase (v. 2.0, U.S. Biochemicals). dITP was employed where sequence was ambiguous, and synthetic oligonucleotides were used as primers to fill any gaps in the nested deletions. The use of gene-specific and P-elementinverted repeat-specific primers to isolate genomic DNA using PCR was described previously in Ballinger and Benzer (1990). Sequences from the 31-bp inverted P-element repeat $1 \mathrm{O}^{\prime}$ Hare and Rubin 1983) and from the $5^{\prime}$ region of the slit transcript were used as primers. Sequencing of PCR products was performed on a Dupont Genesis 2000 sequencing machine after the generation of single-stranded DNA by asymmetric PCR and the removal of excess primers with Sepharose S-200 spin columns. Sequence analysis was accomplished with MacVector (International Biotechnologies) on a Macintosh II. Data base searches and sequence comparisons were conducted using the FASTA package (Pearson and Lipman 1988) with version 23 of the NBRF Database.

Whole-mount in situ hybridizations, enhancer trap detection, and antibody labeling

Whole-mount in situ hybridizations were conducted using digoxigenin-derivatized DNA probes from cDNA B52-5 (Tautz and Pfeiffle 1989). Immunocytochemistry was done essentially as described in Rothberg et al. (1988). Anti- $\beta$-galactosidase antibody (Promega) was used to detect the signal from the enhancer trap constructs and detected with a HRP-conjugated antimouse antibody (Jackson Immunological Laboratories). Signal from whole-mount in situ hybridizations is cytoplasmic (Tautz and Pfeiffle 1989), enhancer trap signal is localized to the nucleus (Bellen et al. 1989), and antibody staining shows both cytoplasmic and cell-surface staining.

\section{Immunoelectron and confocal microscopy}

All preparations were made by dissecting embryos in Schneider medium to expose the nerve cord. Samples were fixed in $2 \%$ paraformaldehyde with $0.025 \%$ glutaraldehyde for $15 \mathrm{~min}$, followed by primary and secondary antibody labeling without detergent. Primary electron microscopy fixation was performed using $2 \%$ glutaraldehyde and $2 \%$ paraformaldehyde prior to 
silver enhancement of signal from the HRP-conjugated secondary (Amersham). The silver enhancement procedure prevents accurate distinctions from being made concerning the relative levels of antigen present among subsets of axons. Samples were treated with $1 \% \mathrm{OsO}_{4}$ and counterstained with uranyl acetate. Sections were prepared on a Reichert ultramicrotome and visualized on a Jeol electron microscope. Confocal images were made using a Bio-Rad MRC 500 system and a Zeiss Axiovert compound microscope.

\section{Immunofluorescence, immunoprecipitations, and immunoblots}

Immunofluorescence of Drosophila S2 cell lines and the preparation of lysates from Canton-S embryos and S2 cell lines (Schneider 1972) were performed essentially as described in Fehon et al. (1990). Immunoprecipitation of protein lysates and S2 cell-conditioned media were performed with anti-slit antibodies followed by the precipitation of the immune complex with protein A-Sepharose 6MD (Pharmacia) or protein A/G beads (Pierce). Samples were suspended in SDS-PAGE loading buffer, boiled, and separated by SDS-PAGE. Following transfer to nitrocellulose, blots were probed with anti-slit antibodies and detected with HRP-conjugated goat anti-rabbit antibodies. No immunoprecipitatable species from KC cell lysates or conditioned media was detected by immunoblotting. Matrix proteins deposited by S2 cells grown in plastic culture flasks |T75; Corning) were prepared, after removal of the cells and three rinses with $1 \times$ PBS, by directly boiling in 300-500 $\mu$ l of SDS. PAGE loading buffer. For immunoblot analysis, 5-10 $\mu$ l was used per lane. Detection of ${ }^{35} \mathrm{~S}$-labeled slit protein in the media was performed by metabolically labeling $10.1 \mathrm{mCi} / \mathrm{ml}$, ICN translabel) S2 cells for $4 \mathrm{hr}$ in M3 media (minus methionine and cysteine), followed by immunoprecipitating the conditioned media with anti-slit antibody and Protein A-Sepharose 6MD. Precipitates were washed overnight in PBS with $1 \%$ bovine serum albumin and $0.1 \%$ Triton, followed by separation with SDS-PAGE and autoradiography.

\section{Acknowledgments}

We thank L. Caron and W. Yu for excellent technical assistance, and B. Shilo for help with whole-mount in situ hybridization. We thank S. Crews for discussions on both the slit and sim phenotypes. Special thanks go to D. Hartley for helpful advice throughout the course of this work. We also give special thanks to A. Kolodkin for the P-element-generated slit alleles. For their comments on the manuscript we thank B. Diederich, H. Keshishian, and especially C. Blaumueller for critical reading of the manuscript. We acknowledge B.J. and M.J. Rothberg for their long-standing support, which made this work possible. J.M.R. was supported by a National Research Service Award. This research was partly supported by National Institutes of Health grants NS26084 awarded to S.A.T.

The publication costs of this article were defrayed in part by payment of page charges. This article must therefore be hereby marked "advertisement" in accordance with 18 USC section 1734 solely to indicate this fact.

\section{References}

Appella, E., I.T. Weber, and F. Blasi. 1988. Structure and function of epidermal growth factor-like regions in proteins. FEBS Lett. 231: 1-4.

Ballinger, D.G. and S. Benzer. 1990. Targeted gene mutations in Drosophila. Proc. Nat1. Acad. Sci. 86: 9402-9406.
Bastiani, M.J. and C.S. Goodman. 1986. Guidance of neuronal growth cones in grasshopper embryo. III. Recognition of specific glial pathways. J. Neurosci. 6: 3542-3551.

Bellen, H.J., C.J. O'Kane, C. Wilson, U. Grossniklaus, R.K. Pearson, and W.J. Gehring. 1989. P-element-mediated enhancer detection: A versatile method to study development in Drosophila. Genes Dev. 3: 1288-1300.

Bier, E., H. Vaessin, S. Shepherd, K. Lee, K. McCall, S. Barbel, L. Ackerman, R. Carnetto, T. Uemura, E. Grell, L.Y. Jan, and Y.N. Jan. 1989. Searching for pattern and mutation in the Drosophila genome with a P-lacZ vector. Genes Dev. 3: $1273-1287$.

Brown, N.M. and F.C. Kafatos. 1988. Functional cDNA libraries from Drosophila embryos. I. Mol. Biol. 203: 425-437.

Cavener, D.R. 1987. Comparison of the consensus sequence flanking translational start sites in Drosophila and vertebrates. Nucleic Acids Res. 15: 1353-1361.

Cooke, R.M., A.J. Wilkinson, M. Baron, A. Pastore, M.J. Tappin, I.D. Campbell, H. Gregory, and B. Sheard. 1987. The solution structure of human epidermal growth factor. Nature 327: 339-341.

Crews, S.T., J.B. Thomas, and C.S. Goodman. 1988. The Drosophila single-minded gene encodes a nuclear protein with sequence similarity to the per gene product. Cell 52: 143-151.

Day, A.A., C.I. McQuillan, J.D. Termine, and M.R. Young. 1987. Molecular cloning and sequence analysis of the cDNA for small proteoglycan II of bovine bone. Biochem. I. 248: 801-805.

Engel, J. 1989. EGF-like domains in extracellular matrix proteins: Localized signals for growth and differentiation? FEBS Lett. 251: 1-7.

Fehon, R.G., P.J. Kooh, I. Rebay, C.L. Regan, T. Xu, M.A.T. Muskavitch, and S. Artavanis-Tsakonas. 1990. Molecular interactions between the protein products of the neurogenic loci Notch and Delta, two EGF-homologous genes in Drosophila. Cell 61: 523-534.

Field, J., H.-P. Xu, T. Michaeli, R. Ballester, P. Sass, M. Wigler, and J. Colicelli. 1990. Mutations of the adenylyl cyclase gene that block RAS function in Saccharomyces cervisiae. Science 247: 464-467.

Fisher, L.W., J.D. Termine, and M.F. Young. 1989. Deduced protein sequence of bone small proteoglycan I (Biglycan) shows homology with proteoglycan II (Decorin) and several nonconnective tissue proteins in a variety of species. J. Biol. Chem. 264: 4571-4576.

Furie, B. and B.C. Furie. 1988. The molecular basis of blood coagulation. Cell 53: 505-518.

Grant, D.S., K. Tashiro, B. Segui-Real, Y. Yamada, G.R. Martin, and H.K. Kleinman. 1989. Two different laminin domains mediate the differentiation of human endothelial cells into capillary-like structures in vitro. Cell 58: 933-943.

Gribskov, M., J. Devereux, and R.B. Burgess. 1984. The codon preference plot: Graphic analysis of protein coding sequences and prediction of gene expression. Nucleic Acids Res. 12: 539-549.

Handford, P.A., M. Baron, M. Mayhew, A. Willis, T. Beesley, G.G. Brownlee, and I.D. Campbell. 1990. The first EGF-like domain from human factor IX contains a high-affinity calcium binding site. EMBO J. 9: 475-480.

Hartenstein, V. and J.A. Campos-Ortega. 1985. The embryonic development of Drosophila melanogaster. Springer-Verlag, Berlin.

Hashimoto, C., K.L. Hudson, and K.V. Anderson. 1988. The Toll gene of Drosophila, required for dorsal-ventral embryonic polarity, appears to encode a transmembrane protein. Cell 52: 269-279. 
Hedbom, E. and D. Heinegård. 1989. Interactions of 59-kDa connective tissue matrix protein with collagen I and collagen II. J. Biol. Chem. 264: 6898-6905.

Hickey, M.J., S.A. Williams, and G.J. Roth. 1989. Human platelet glycoprotein IX: An adhesive prototype of leucinerich glycoproteins with flank-center-flank structures. Proc. Natl. Acad. Sci. 86: 6773-6777.

Hiromi, Y., A. Kuroiwa, and W.J. Gehring. 1985. Control elements of the Drosophila segmentation gene fushi tarazu. Cell 43: 603-613.

Hultmark, D., R. Klemenz, and W.J. Gehring. 1986. Translational and transcriptional control elements in the untranslated leader of the heat-shock gene hsp22. Cell 44: 429-438.

1988. Neurite extension of chicken peripheral nervous system neurons on fibronectin: Relative importance of specific adhesion sites in the central cell-binding domain and the alternatively spliced type III connecting segment. I. Cell Biol. 106: 1289-1297.

Ingber, D.E. and J. Folkman. 1989. How does the extracellular matrix control capillary morphogenesis? Cell 58: 803-805.

Jacobs, J.R. and C.S. Goodman. 1989a. Embryonic development of axon pathways in the Drosophila CNS. 1. A glial scaffold appears before the first growth cones. I. Neurosci. 9: 24022411.

- 1989b. Embryonic development of axon pathways in the Drosophila CNS. II. Behavior of pioneer growth cones. I. Neurosci. 9: 2412-2422.

Jan, L.Y. and Y.N. Jan. 1982. Antibodies to horseradish peroxidase as specific neuronal markers in Drosophila and grasshopper embryos. Proc. Natl. Acad. Sci. 79: 2700-2704.

Jessell, T.M. 1988. Adhesion molecules and the hierarchy of neural development. Neuron 1: 3-13.

Kataoka, T., D. Broek, and M. Wigler. 1985. DNA sequence and characterization of the $S$. cerevisiae gene encoding adenylate cyclase. Cell 43: 493-505.

Kopczynski, C.C., A.K. Alton, K. Fechtel, P.J. Kooh, and M.A.T. Muskavitch. 1988. Delta, a Drosophila neurogenic gene, is transcriptionally complex and encodes a protein related to blood coagulation factors and epidermal growth factor of vertebrates. Genes Dev. 2: 1723-1735.

Krantz, D.E. and S.L. Zipursky. 1990. Drosophila chaoptin, a member of the leucine-rich repeat family, is a photoreceptor cell-specific adhesion molecule. EMBO /. 9: 1969-1977.

Krusius, T. and E. Ruoslahti. 1986. Primary structure of an extracellular matrix proteoglycan core protein deduced from cloned cDNA. Proc. Natl. Acad. Sci. 83: 7683-7687.

Lander, A.D. 1989. Understanding the molecules of neural cell contacts: Emerging patterns of structure and function. Trends Neurosci. 12: 189-195.

Larson, R.S., A.L. Corbi, L. Berman, and T. Springer. 1989. Primary structure of the leukocyte function-associated molecule-1 $\alpha$ subunit: An integrin with an embedded domain defining a protein superfamily. J. Cell Biol. 108: 703-712.

Leptin, M., T. Bogaert, R. Lehmann, and M. Wilcox. 1989. The function of PS integrins during Drosophila embryogenesis. Cell 56: 401-408.

Lopez, J.A., D.W. Chung, K. Fujikawa, F.S. Hagen, E.W. Davie, and G.J. Roth. 1987. Cloning of the $\alpha$ chain of human platelet glycoprotein Ib: A transmembrane protein with homology to leucine-rich $\alpha_{2}$-glycoprotein. Proc. Natl. Acad. Sci. 84: 5615-5619.

- 1988. The $\alpha$ and $\beta$ chains of human platelet glycoprotein IB are both transmembrane proteins containing a leucine-rich amino acid sequence. Proc. Natl. Acad. Sci. 85: $2135-2139$.
Maniatis, T., E.F. Fritsch, and J. Sambrook. 1982. Molecular cloning: A laboratory manual. Cold Spring Harbor Laboratory, Cold Spring Harbor, New York.

McDonald, J.A. 1989. Matrix regulation of cell shape and gene expression. Curr. Opin. Cell Biol. 1: 995-999.

McFarland, K.C., R. Sprengel, H.S. Phillips, M. Köhler, N. Rosemblit, K. Nikolics, D.L. Segaloff, and P.H. Seeberg. 1989. Lutropin-choriogonadotropin receptor: An unusual member of the G protein-coupled receptor family. Science 245: 494499.

Mikol, D.D., J.R. Gulcher, and K. Stefansson. 1990. The oligodendrocyte-myelin glycoprotein belongs to a distinct family of proteins and contains the HNK-1 carbohydrate. I. Cell Biol. 110: 471-479.

Mohri, H., Y. Fujimura, M. Shima, A. Yoshioka, R.A. Houghten, Z.M. Ruggeri, and T.S. Zimmerman. 1988. Structure of the von Willebrand factor domain interacting with glycoprotein Ib. I. Biol. Chem. 263: 17901-17904.

Montell, D.J. and C.S. Goodman. 1989. Drosophila laminin: Sequence of $\beta 2$ subunit and expression of all three subunits during embryogenesis. I. Cell Biol. 109: 2441-2453.

Newman, S.M. Jr. and R.F. Wright. 1981. A histological and ultrastructural analysis of developmental defects produced by the mutation, lethal $(1)$ myospheroid, in Drosophila melanogaster. Dev. Biol. 86: 393-402.

O'Hare, K. and G.M. Rubin. 1983. Structure of $P$ transposable elements and their sites of insertion and excision in the Drosophila melanogaster genome. Cell 34: 25-35.

Oldberg, A., P. Antonsson, K. Lindblom, and D. Heinegard. 1989. A collagen-binding 59-kd protein (fibromodulin) is structurally related to the small interstitial proteoglycans PG-S1 and PG-S2 (decorin). EMBO I. 8: 2601-2604.

Pearson, W.R. and D.J. Lipman. 1988. Improved tools for biological sequence comparison. Proc. Natl. Acad. Sci. 85: 24442448.

Poole, S.J., L.M. Kauvar, B. Drees, and T. Kornberg. 1985. The engrailed locus of Drosophila: Structural analysis of an embryonic transcript. Cell 40: 37-43.

Poulson, D.F. 1950. Histogenesis, organogenesis, and differentiation in the embryo of Drosophila melanogaster meigen. In Biology of Drosophila (ed. M. Demerec), pp. 168-274. Wiley, New York.

Rees, D.J.G., I.M. Jones, P.A. Handford, S.J. Walter, M.P. Esnouf, K.J. Smith, and G.G. Brownlee. 1988. The role of $\beta$-hydroxyaspartate and adjacent carboxylate residues in the first EGF domain of human factor IX. EMBO J. 7: 2053-2061.

Reinke, R., D.E. Krantz, D. Yen, and S.L. Zipursky. 1988. Chaoptin, a cell surface glycoprotein required for Drosophila photoreceptor cell morphogenesis, contains a repeat motif found in yeast and human. Cell 52: 291-301.

Rothberg, J.M., D.A. Hartley, Z. Walther, and S. Artavanis-Tsakonas. 1988. slit: An EGF-homologous locus of D. melanogaster involved in the development of the embryonic central nervous system. Cell 55: 1047-1059.

Rutishauser, U. 1989. Neural cell-to-cell adhesion and recognition. Curr. Opin. Cell Biol. 1: 898-904

Rutishauser, U. and T.M. Jessell. 1988. Cell adhesion molecules in vertebrate neural development. Physiol. Rev. 68: $819-857$.

Saiki, R.K., D.H. Gelfand, S. Stoffel, S.J. Scharf, R. Higuchi, G.T. Horn, K.B. Mullis, and H.A. Erlich. 1988. Primer-directed enzymatic amplification of DNA with a thermostable DNA polymerase. Science 239: 487-491.

Sanes, J.R. 1989. Extracellular matrix molecules that influence neural development. Annu. Rev. Neurosci. 12: 491-516. 
Sanger, F., S. Nicklen, and A.R. Coulson. 1977. DNA sequencing with chain-terminating inhibitors. Proc. Natl. Acad. Sci. 74: 5463-5467.

Schmidt, G., H. Robeneck, B. Harrach, J. Glössl, V. Nolte, H. Hörmann, H. Richter, and H. Kresse. 1987. Interactions of small dermatan sulfate proteoglycan from fibroblasts with fibronectin. I. Cell Biol. 104: 1683-1691.

Schneider, I. 1972. Cell lines derived from late embryonic stages of Drosophila melanogaster. J. Embryol. Exp. Morphol. 27: 353-365.

Schneider, R., E. Schneider-Scherzer, M. Thurnher, B. Auer, and M. Schweiger. 1988. The primary structure of human ribonuclease/angiogenin inhibitor (RAI) discloses a novel highly diversified protein superfamily with a common repetitive module. EMBO 1. 7: 4151-4156.

Takahashi, N., Y. Takahashi, and F.W. Putnam. 1985. Periodicity of leucine and tandem repetition of a 24-amino acid segment in the primary structure of leucine-rich a2-glycoprotein of human serum. Proc. Natl. Acad. Sci. 84: 47674771.

Tautz, D. and C. Pfeiffle. 1989. A non-radioactive in situ hybridization method for the localization of specific RNAs in Drosophila embryos reveals translational control of the segmentation gene hunchback. Chromosoma 98: 81-85.

Thomas, J.B., S.T. Crews, and C.S. Goodman. 1988. Molecular genetics of the single-minded locus: A gene involved in the development of the Drosophila nervous system. Cell 52: $133-141$.

Titani, K., K. Takio, M. Handa, and Z.M. Ruggeri. 1987. Amino acid sequence of the von Willebrand factor-binding domain of platelet membrane glycoprotein Ib. Proc. Natl. Acad. Sci. 84: $5610-5614$.

Vassin, H., K.A. Bremer, E. Knust, and J. Campos-Ortega. 1987. The neurogenic gene Delta of Drosophila melanogaster is expressed in neurogenic territories and encodes a putative transmembrane protein with EGF-like repeats. EMBO $\%$ 6: $3431-3440$.

Vernadakis, A. 1988. Neuron-glia interrelations. Int. Rev. Neurobiol. 30: 149-224.

Vogel K.G., M. Paulsson, and D. Heinega ${ }^{\circ}$ rd. 1984. Specific inhibition of type I and type II collagen fibrillogenesis by the small proteoglycan of tendon. Biochem. I. 223: 587-597.

von Heijne, G. 1986. A new method for predicting signal sequence cleavage sites. Nucleic Acids Res. 14: 4683-4690.

Wharton, K.A., K.M. Johansen, T. Xu, and S. Artavanis-Tsakonas. 1985. Nucleotide sequence from the neurogenic locus Notch implies a gene product that shares homology with proteins containing EGF-like repeats. Cell 43: 567581.

Yamaguchi, Y. and E. Ruoslahti. 1988. Expression of human proteoglycan in Chinese hamster ovary cells inhibits cell proliferation. Nature 336: 244-246.

Yarden, Y. and A. Ullrich. 1988. Growth factor receptor tyrosine kinases. Annu. Rev. Biochem. 57: 443-478.

Zak, N.B., R.J. Wides, E.D. Schejter, E. Raz, and B. Shilo. 1990. Localization of the DER/flb protein in embryos: Implications on the faint little ball lethal phenotype. Development 109: 865-874. 


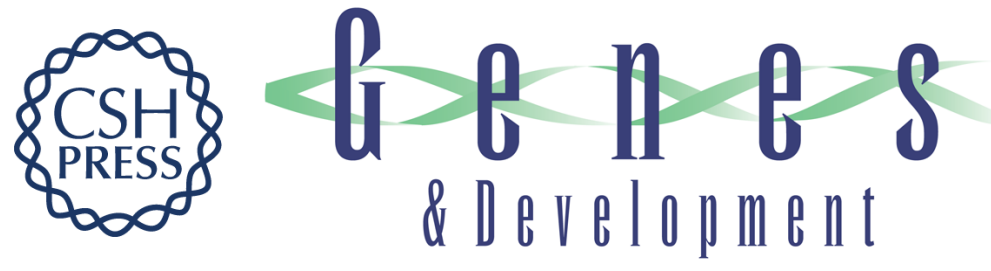

\section{slit: an extracellular protein necessary for development of midline glia and commissural axon pathways contains both EGF and LRR domains.}

J M Rothberg, J R Jacobs, C S Goodman, et al.

Genes Dev. 1990, 4:

Access the most recent version at doi:10.1101/gad.4.12a.2169

References This article cites 71 articles, 28 of which can be accessed free at:

http://genesdev.cshlp.org/content/4/12a/2169.full.html\#ref-list-1

License

Email Alerting

Service

Receive free email alerts when new articles cite this article - sign up in the box at the top right corner of the article or click here.

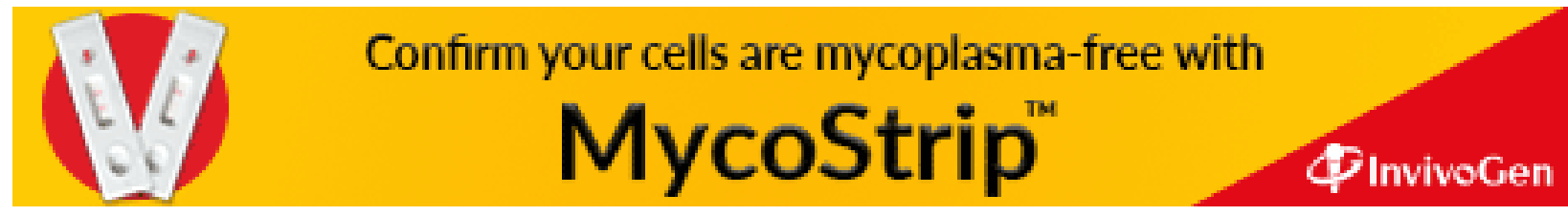

